ISSN: 0514-7336

DOI: http://dx.doi.org/10.14201/zephyrus2016773157

\title{
EXPERIMENTACIÓN CON PROYECTILES DE RETOQUE PLANO Y RESULTADOS DE SU ANÁLISIS FUNCIONAL
}

\section{Experimentation with projectiles of flat retouch and their functional analysis results}

\author{
María Amparo Laborda Martínez \\ Dpto. de Historia, Historia del Arte y Geografía. Facultad de Filosofía y Letras. Universidad de Navarra. \\ Campus Universitario.31080 Pamplona (Navarra).Correo-eampalaborda@hotmail.es
}

Recepción: 3/10/2015; Revisión: 6/02/2016; Aceptación: 24/03/2016

\begin{abstract}
Resumen: Un variado repertorio de construcciones de arquitectura monumental, localizadas en la cuenca alta y media del valle del Ebro, se han interpretado como tumbas colectivas de uso diacrónico a lo largo del III milenio a. C. Numerosas son las puntas de flecha recuperadas en los depósitos de algunas de sus cámaras mortuorias. La mayor parte se registran entre los restos esqueléticos y unas pocas clavadas en huesos de algunos de los individuos inhumados. En este trabajo se pretende reconstruir su función como proyectiles mediante la experimentación y la traceología, con el fin de aproximarnos al significado de estas armas en contextos funerarios y tomando como referencia las colecciones de puntas procedentes de los dólmenes de Aizibita y Charracadía (valle del Salado, Navarra). El programa experimental desarrollado ha incluido la utilización de puntas de flecha de retoque plano, de diferentes morfologías, fabricadas en sílex y propulsadas con arco. Se ha llevado a cabo una sesión de tiro, durante la cual las réplicas se dispararon del modo más ajustado a la supuesta realidad prehistórica. Un posterior análisis traceológico ha permitido identificar estigmas de impacto de naturaleza macro- y microscópica. A partir de los resultados obtenidos se abordan cuestiones relativas a la efectividad, uso y vida útil de estos proyectiles líticos.
\end{abstract}

Palabras clave: Arqueología experimental; análisis de huellas de uso; punta de flecha; sílex.

ABSTRACT: A varied repertoire of buildings of monumental architecture, which are located in the upper and middle basin of the Ebro valley, have been interpreted as collective graves of diachronic use along the III millennium BC. Numerous arrowheads have been recovered in the filling deposits of some burial chambers. Most of them have been registered among the skeletal remains, but only very few of them were nailed in bones of certain buried individuals. The purpose of this work is to reconstruct its function as projectiles through experimentation and traceology, with the aim of approaching to the meaning of these weapons in funerary contexts, and taking the arrowheads collections from the dolmens of Aizibita and Charracadía (Salado valley, Navarre) as a reference. The experimental program developed has included the use of different morphologies of flint arrowheads of flat retouch which were propelled by bow. A session of shot has been carried out, during which the replicas were fired in the most adjusted way to the alleged prehistoric reality. A subsequent use-wear analysis has identified impact traces of macroscopic and microscopic nature. Issues relating to effectiveness, use and longevity of these lithic projectiles are addressed from the obtained results.

Key words: Experimental archeology; use-wear analysis; arrowhead; silex. 


\section{Introducción}

Las puntas de retoque plano son un tipo de arma lítica imperante en la panoplia de las poblaciones calcolíticas de la cuenca alta y media del valle del Ebro durante el III milenio a. C. Estos proyectiles, que se fabricaron para armar flechas, sin duda fueron necesarios para desarrollar actividades cinegéticas y se utilizaron en enfrentamientos interpersonales o conflictos intragrupales (Etxeberria y Vegas, 1988; Márquez et al., 2008; Liseau et al., 2014; Piqué et al., 2015). Se atestiguan en ámbitos domésticos y es recurrente su presencia en sepulcros megalíticos y otros lugares de enterramiento adscritos al momento de transición del Neolítico al Calcolítico, como el ejemplo bien conocido de San Juan ante Portam Latinam (Álava), que se relaciona con un episodio belicoso que causó la muerte de algunos de los individuos allí inhumados (Etxeberria y Herrasti, 2007). Dentro de este marco regional, en la Zona Media del actual territorio navarro, destacan un conjunto de construcciones funerarias, con distintas arquitecturas monumentales, cuyos depósitos arqueológicos han deparado lotes numerosos de

1 Son muchas las personas e instituciones que, de un modo u otro, han contribuido a que esta investigación llegara a buen término. En primer lugar, la Universidad de Navarra y su Dpto. de Historia, Historia del Arte y Geografía y, en especial, la Dra. M. A. Beguiristain, cuyo estímulo y decidida voluntad facilitaron el proceso de desarrollo del trabajo. Le agradezco asimismo las gestiones realizadas al efecto con A. Oyarzun, miembro de la Asociación de Cazadores Deportivos de Atez Gascue.

Esta iniciativa hubiera sido difícil de materializar sin la colaboración del director del proyecto en el que se inserta este estudio, Dr. J. A. Mujika, de la Universidad del País Vasco, y también de la Dra. M. Rojas, autora de la fabricación de las réplicas utilizadas en la experimentación.

Igualmente quiero expresar mi agradecimiento a J. Zumeta, experto arquero, y a A. Arrese, de la empresa Suhar Arkeologia, que participaron en el montaje de las flechas, por su buena disposición para la adecuada práctica de la sesión de tiro. Por último, estoy en deuda con la desinteresada ayuda que me ha dispensado G. Oyarzun, quien realizó un detallado registro fotográfico de campo, y el Dr. J. Sesma, artífice de algunas de las fotografías de laboratorio. A todos ellos, mi más sincera gratitud. puntas. Nos referimos al hipogeo de Longar (Viana) y a los dólmenes de Aizibita y Charracadía, ambos situados en el valle del río Salado (Armendáriz e Irigaray, 1993-1994; Beguiristain, 2007)2. En los dos primeros monumentos megalíticos existen además testimonios de actos de violencia, en el caso de Longar son varias las inhumaciones asociadas a lesiones por puntas de flecha (Armendáriz et al., 1994; Armendáriz e Irigaray, 1995: 26; Beguiristain y Etxeberria, 1994).

Análisis funcionales de piezas prehistóricas similares procedentes de espacios sepulcrales han propuesto su uso como proyectiles y sugerido que pudieran haber llegado a las cámaras mortuorias alojados en los cuerpos de ciertos individuos ( $\mathrm{Pa}-$ lomo y Gibaja, 2003; Márquez, 2007). Desde esta óptica, ahondar acerca de su utilización podía permitir aproximarnos a la interpretación de estos objetos en el seno de los contextos funerarios en los que fueron hallados, a la par que complementar las rigurosas analíticas tecnotipológicas en las que se ha centrado hasta ahora el interés de la investigación (Cava, 1984; Beguiristain, 2011). Con el presente estudio, realizado en el marco de un proyecto ${ }^{3}$ más amplio, abordamos la reconstrucción del uso de las puntas a partir de las propuestas metodológicas propias de la traceología. Para ello hemos desarrollado una experimentación de tiro con arco y un minucioso análisis microscópico a bajos y altos aumentos. Los resultados obtenidos se han utilizado de referente previo al estudio en curso sobre las puntas de retoque plano recuperadas en los citados dólmenes del Salado, con el fin de comprender mejor las prácticas y comportamientos que afectan, en último término, a la esfera territorial, social y simbólica de estas comunidades.

2 Cf. también Vélaz, D.: El megalitismo en el valle del Salado (Navarra): un estudio territorial desde los Sistemas de Información Geográfica, 2 vols. Tesis doctoral inédita defendida en 2003 en la Univ. de Navarra.

3 Proyecto HAR2011-26956: Estudio de las relaciones entre las poblaciones megalíticas en el Pirineo occidental y su entorno a través de los enterramientos, asentamientos, ajuares y ADNmt, dirigido por J. A. Mujika, de la Univ. del País Vasco. 


\section{Protocolo experimental}

\subsection{Las puntas y el montaje de las flechas}

Dada la naturaleza y objetivos del estudio, que requiere una notable inversión de tiempo y esfuerzo -se trata de una tarea que difícilmente puede afrontarse de manera individual, entre otras razones, por la dificultad técnica que implica la elaboración de las puntas, los propios costes de producción y el carácter artesanal de la fabricación de las flechas, además de los imperativos de contar con un/a tallista experimentado y un arquero/a para la ejecución práctica de los tiros experimentales-, y tomando como referencia otros estudios funcionales ya publicados, se planificó limitar el objeto de análisis a una pequeña muestra de puntas (Lombard y Parteger, 2008: 2525). Consideramos que la reducida colección experimental era representativa del material arqueológico que estudiaríamos en un futuro y lo suficientemente abarcable para controlar con ciertas garantías una sesión de tiro y abordar después un detallado análisis traceológico.

Un conjunto de 27 puntas, con distintos niveles de dificultad técnica, fueron realizadas por la Dra. Maite García. Para la obtención de los soportes recurrió a la percusión directa y en la conformación final de las piezas se llevó a cabo, mediante presión, una reducción bifacial por medio de un compresor con punta de cobre (Fig. 1a-d). Los retoques planos
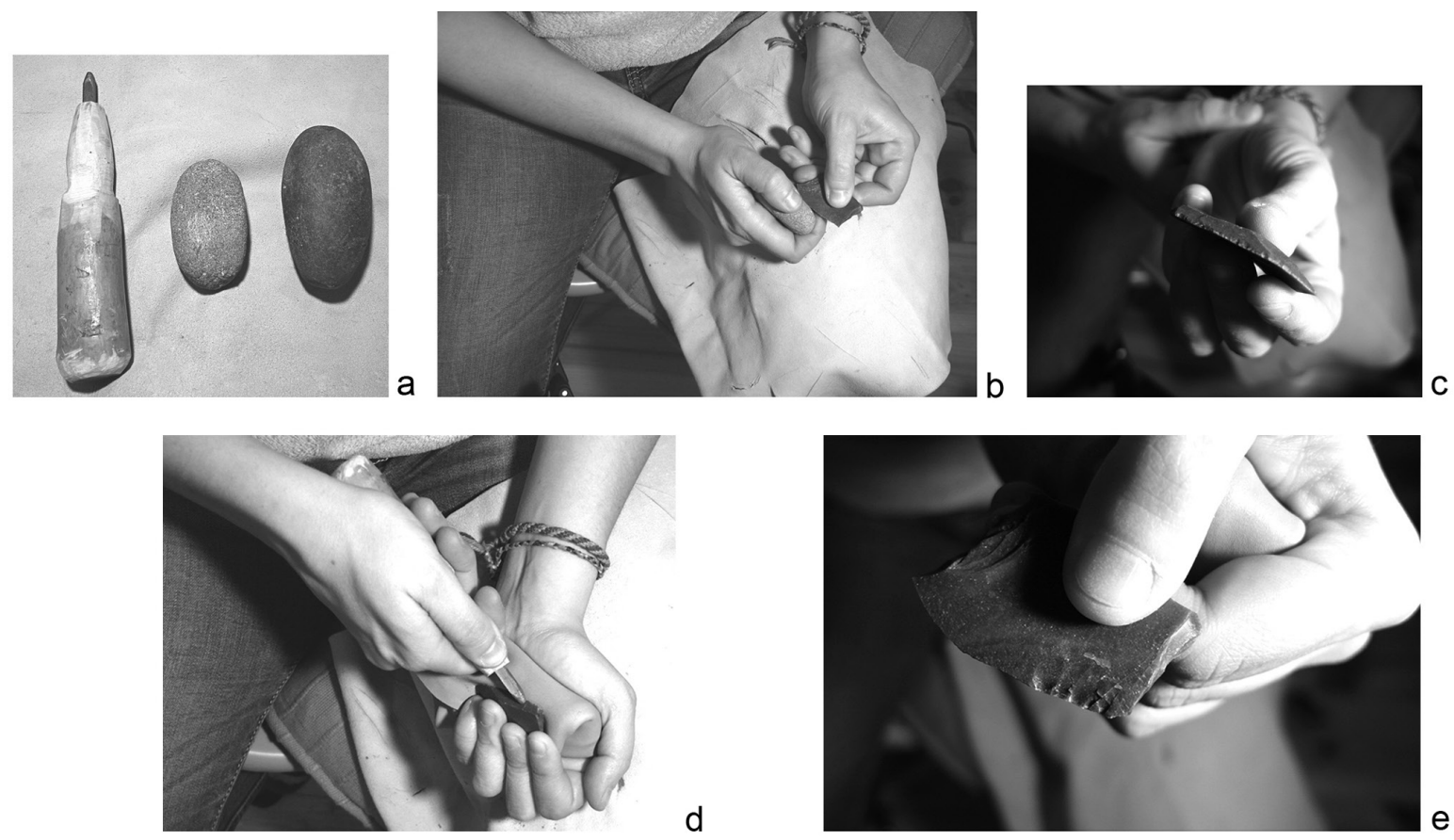

d
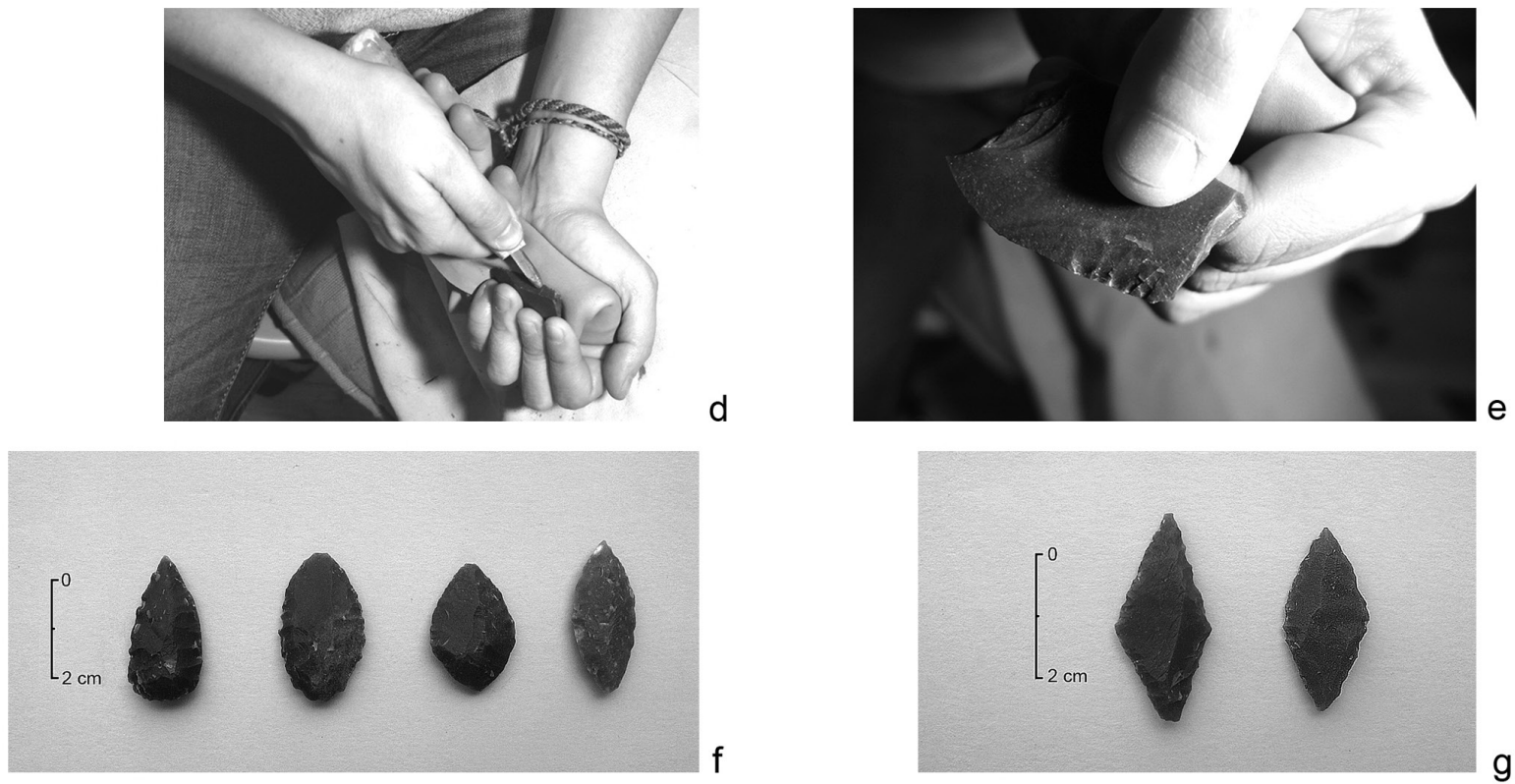

Fig. 1. Fabricación de las puntas. 

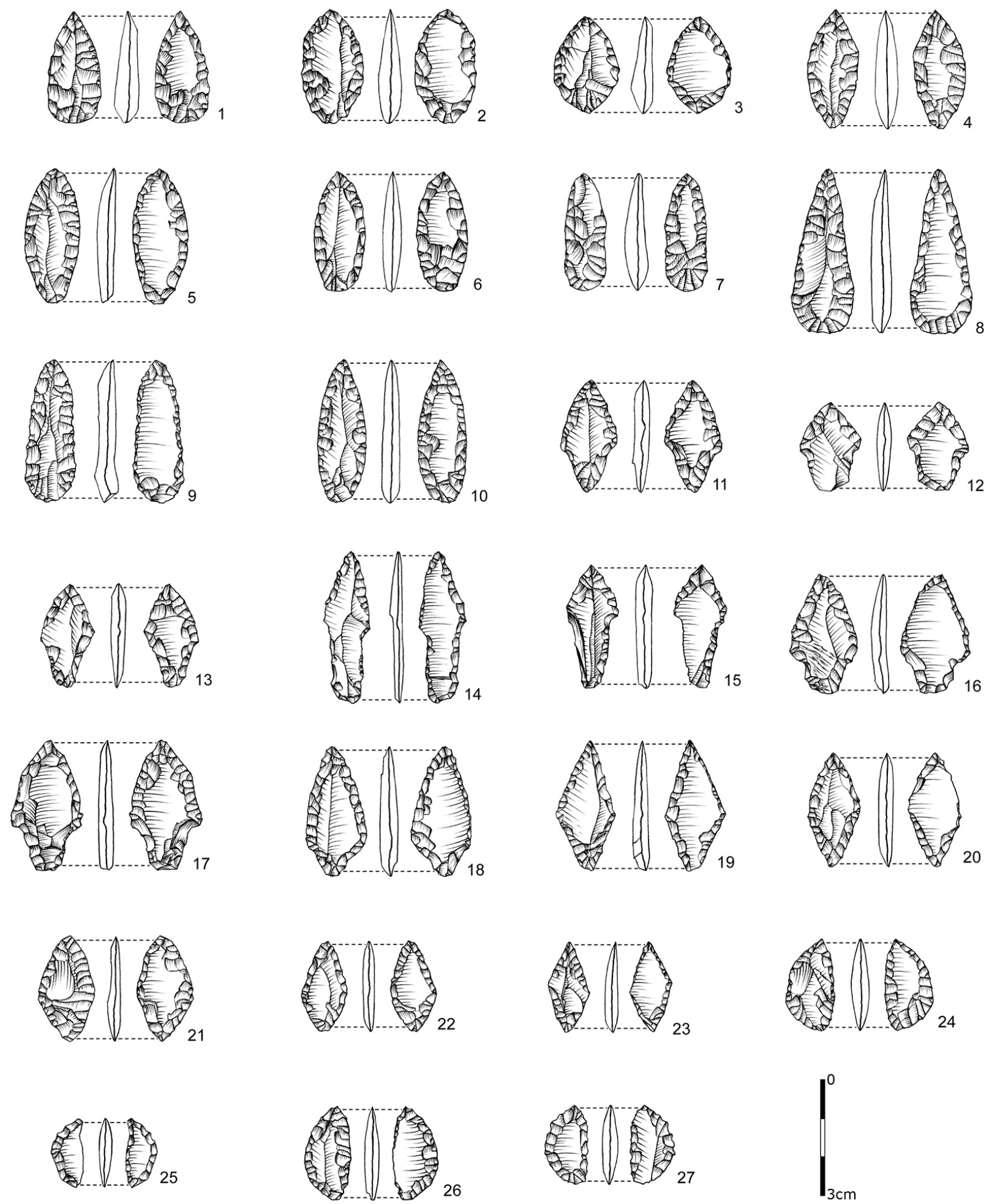

Fig. 2. Puntas experimentales. 
y cortos, no cubrientes, regularizaron los perímetros de las armaduras, sin llegar a adelgazar demasiado el espesor de alguna de ellas (Fig. 1e-g). El uso del compresor metálico provocó en ocho de las puntas unos diminutos y difusos brillos macroscópicos de color rojizo, localizados principalmente en algunas de las aristas de las extracciones situadas en las zonas basales o en los pedúnculos. Estas huellas tecnológicas desaparecieron tras una limpieza con agua y jabón.

En la selección de variedades silíceas a explotar se ha tenido en cuenta la determinación de la procedencia de los sílex de las puntas prehistóricas recuperadas en las tumbas megalíticas del valle del Salado ${ }^{4}$. Domina el sílex local de las canteras próximas de la sierra de Urbasa, pero, dada la dificultad de obtener materia prima de dichos afloramientos, se optó por otro sílex, también representado en la muestra, pero en menor proporción, y que proviene de las formaciones del Flysch de Barrica (Vizcaya). Con este se confeccionó la práctica totalidad de las réplicas, excepto una pieza fabricada en sílex melado de excelente calidad de Bergerac (Francia). Las cualidades del sílex elegido, con un grano de textura fina y color gris oscuro, favorecían además una buena visualización microscópica de su superficie.

\subsubsection{Características de las réplicas}

A partir de la cuidada factura y el análisis tecnomorfológico de las armaduras prehistóricas, colegimos que la propulsión experimental de estas puntas, con el fin de comprobar su comportamiento balístico, requería una serie de exigencias relacionadas con el tipo de enmangue y con una cierta uniformidad en los parámetros relativos a la simetría de las morfologías, las proporciones de las diferentes partes de los proyectiles y el pequeño tamaño y reducido peso de las puntas ( $c f$. Fig. 12).

Respecto a las morfologías, están representados los tipos primarios más numerosos hallados en las estructuras dolménicas mencionadas (Beguiristain, 2007; Vélaz, 2003), principalmente el foliforme con base apuntada o convexa (10 ejemplares reproducidos; Fig. 2, n. ${ }^{\text {os }} 1-10$ ); puntas pedunculadas con

\footnotetext{
${ }^{4}$ Propuesta por A. Tarriño (com. personal).
}

aletas en apéndice o apenas protuberantes, tanto simétricas como mostrando una leve asimetría axial, conformadas con espigas de diferentes longitudes (8 piezas; Fig. 2, n. ${ }^{\text {os }}$ 11-18); romboidales (5 armaduras; Fig. 2, n. ${ }^{\text {os }} 19-23$ ), y segmentiformes (4 puntas; Fig. 2, n. ${ }^{\text {s }}$ 24-27). Se ha excluido la morfología de pedúnculo y aletas desarrolladas porque, aunque son frecuentes por ejemplo en el dolmen de Charracadía, han sido objeto de otros programas experimentales específicos (Palomo y Gibaja, 2002, 2003).

Los módulos dimensionales de las réplicas se aproximan a los de las piezas prehistóricas y para ello se tomaron como referencia aquellas puntas que se conservaban completas o en las que era posible reconstruir su tamaño original. En la Fig. 3 se ofrece una comparativa dimensional con la población arqueológica de referencia y se aprecian las diferencias métricas entre los componentes de la muestra experimental. En estos últimos, las medias de longitud y anchura indican que las puntas más largas y anchas son las foliformes y las pedunculadas con aletas en apéndice $-32,2$ x 14,25 mm y 31,4 x $15 \mathrm{~mm}$ respectivamente-. En un segmento métrico más pequeño se incluye el grupo de las puntas romboidales -27,2 x 13,4 mm- y las magnitudes más cortas y estrechas corresponden a las piezas segmentiformes -21,3 x 10,8 mm-.

En cuanto a los espesores medios, son bastante homogéneos, predominan las puntas con $4 \mathrm{~mm}$ de grosor -el 37,03\% del total, las más representadas, las pedunculadas-, si bien se registran oscilaciones superiores en las armaduras foliformes $-6 / 7 \mathrm{~mm}-\mathrm{y}$ menores en las romboidales $-3 / 3,5 \mathrm{~mm}-$. Para evitar una sobrecarga en el extremo superior de los astiles y compensar el balance adecuado de las flechas, las puntas debían ser ligeras de peso, los tipos de fisonomía más robusta, foliformes, alcanzan una media de 2,68 g, seguidos de aquellos dotados de pedúnculo y aletas en apéndice $-1,83 \mathrm{~g}$-; el resto de las categorías se pueden considerar bastante livianas, con valores medios que fluctúan entre 1,26 g las romboidales y $0,95 \mathrm{~g}$ las armaduras segmentiformes.

Se han medido también los ángulos apicales ( $c f$. Fig. 12) para comprobar su influencia en la penetración de las puntas y tratar de determinar posibles 

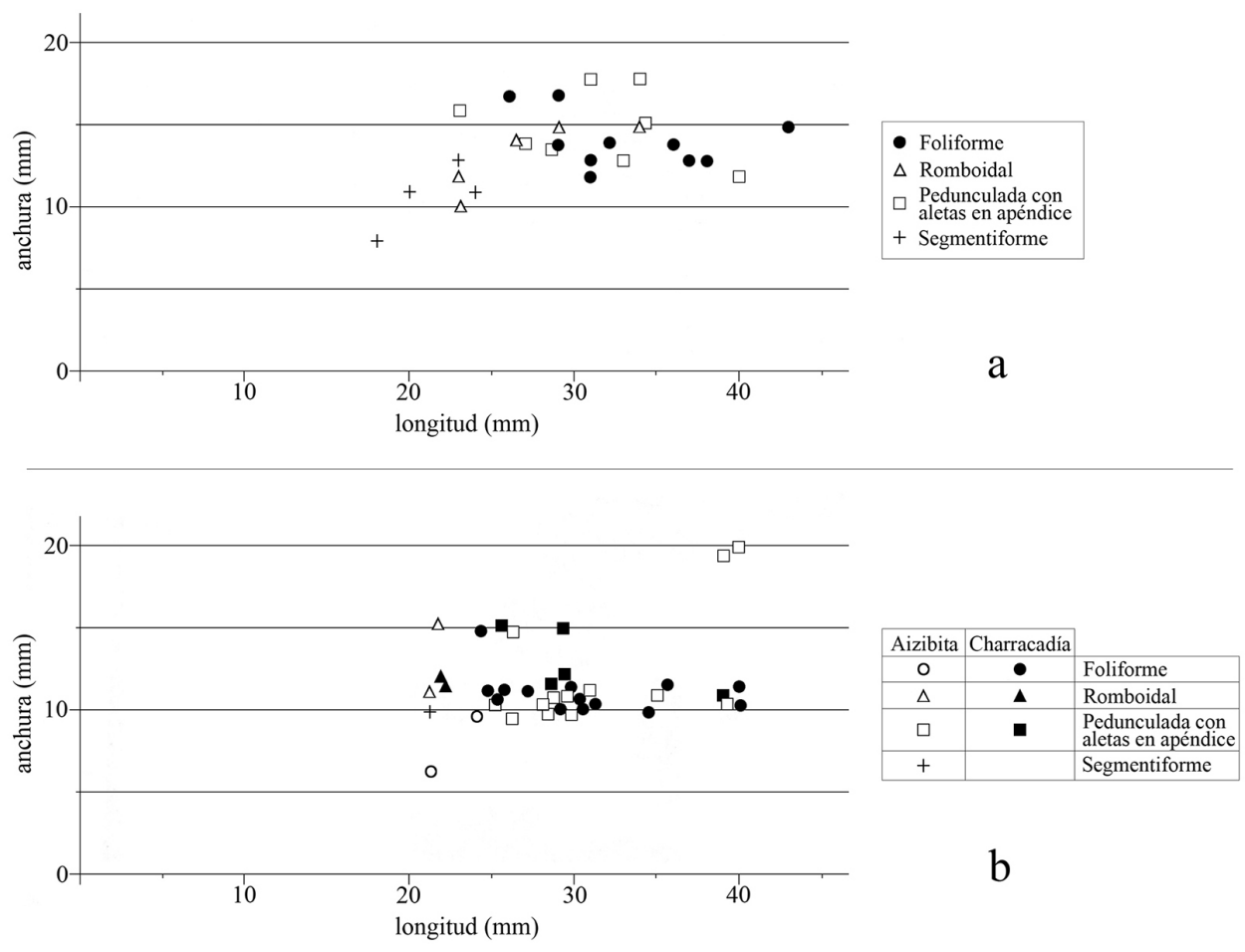

FIG 3. Relación longitudlanchura según las diferentes morfologías de las puntas.

dimensiones que garantizaban la estabilidad de la trayectoria de las flechas. Los astiles se identificaron con un número arábigo correlativo, coincidente con el de las armaduras. El sistema de sujeción ha consistido en introducir las piezas en la zona distal de los vástagos dentro de unas hendiduras a modo de horquilla, alineando sus ejes longitudinales en paralelo a los ejes de las flechas (Fig. $5 \mathrm{a}$ y b), excepto un enmangue oblicuo

limitaciones balísticas. La distribución de los mismos según tipos, expresada en la Fig. 4, se caracteriza por un predominio de los ángulos superiores a $70^{\circ}$ en los foliformes, presentes en el $50 \%$ de las piezas. El intervalo comprendido entre $60^{\circ}-70^{\circ}$ se ha registrado en todas las morfologías, con valores oscilantes, del $50 \%$ en los ejemplares pedunculados con aletas apenas esbozadas y en los segmentiformes, y frecuencias menores en las armaduras foliformes y romboidales. Proporciones variables, pero discretas, muestran todas las categorías respecto a los ángulos agrupados entre $50^{\circ}-60^{\circ}$ y es escasa la representatividad de las puntas más agudas $\left(40^{\circ}-50^{\circ}\right)$, siendo los ejemplares catalogados como romboidales los que ofrecen un mayor porcentaje $-40 \%$-, seguidos a gran distancia de los foliformes $-10 \%-$.

\subsubsection{El montaje de las flechas}

Cada punta se insertó en una varilla de pino -Pinus sylvestris- de fabricación industrial, con una longitud de $77 \mathrm{~cm}$ y un diámetro de $9 \mathrm{~mm}$, aplicado a una punta segmentiforme (Fig. 5c), con el fin de probar su capacidad de penetración. Se ataron con cordeles y fijaron con un adhesivo natural que los recubría, resultante de la mezcla caliente de resina de pino y cera natural de abeja, emulsionada con ceniza. De este modo se reforzó la solidez del conjunto.

En la zona proximal del astil se practicó una entalladura, de $4 \mathrm{~mm}$ de profundidad, que constituye el culatín para ajustar la cuerda del arco (Fig. 5d) y se colocaron, a $35 \mathrm{~mm}$ de distancia del mismo, los estabilizadores de vuelo, tres plumas artificiales de plástico, cortadas a medida a distintas larguras, comprendidas entre 11, 15 y $17 \mathrm{~cm}$. Estaban dispuestas de forma radial, con sus raquis encolados al vástago y aseguradas con finas cuerdas en los extremos (Fig. 5e).

El peso total de las flechas montadas variaba según el tipo de punta engastado, siendo las armadas con réplicas foliformes las más pesadas -media: $35,7 \mathrm{~g}-\mathrm{y}$ aquellas con ejemplares segmentiformes 
las más ligeras de la muestra -media: 29,2 g-. Las flechas con cabezales de morfología romboidal o equipadas de pedúnculo y aletas incipientes presentaban pesos medios similares $-33,8 \mathrm{~g}$ y 33,7 g respectivamente-. Estos rangos, acordes con los constatados en ejemplares etnográficos actuales (Cattelain, 1997: 229), garantizaban que las masas a desplazar durante la propulsión favorecieran la velocidad y estabilidad del vuelo de las flechas, así como una penetración efectiva.

\subsection{La sesión de tiro}

La sesión de tiro experimental se efectuó en diciembre de 2013, en la localidad de Guelbenzu (valle de Odieta, al no de Navarra). El lugar elegido fue un camino ubicado
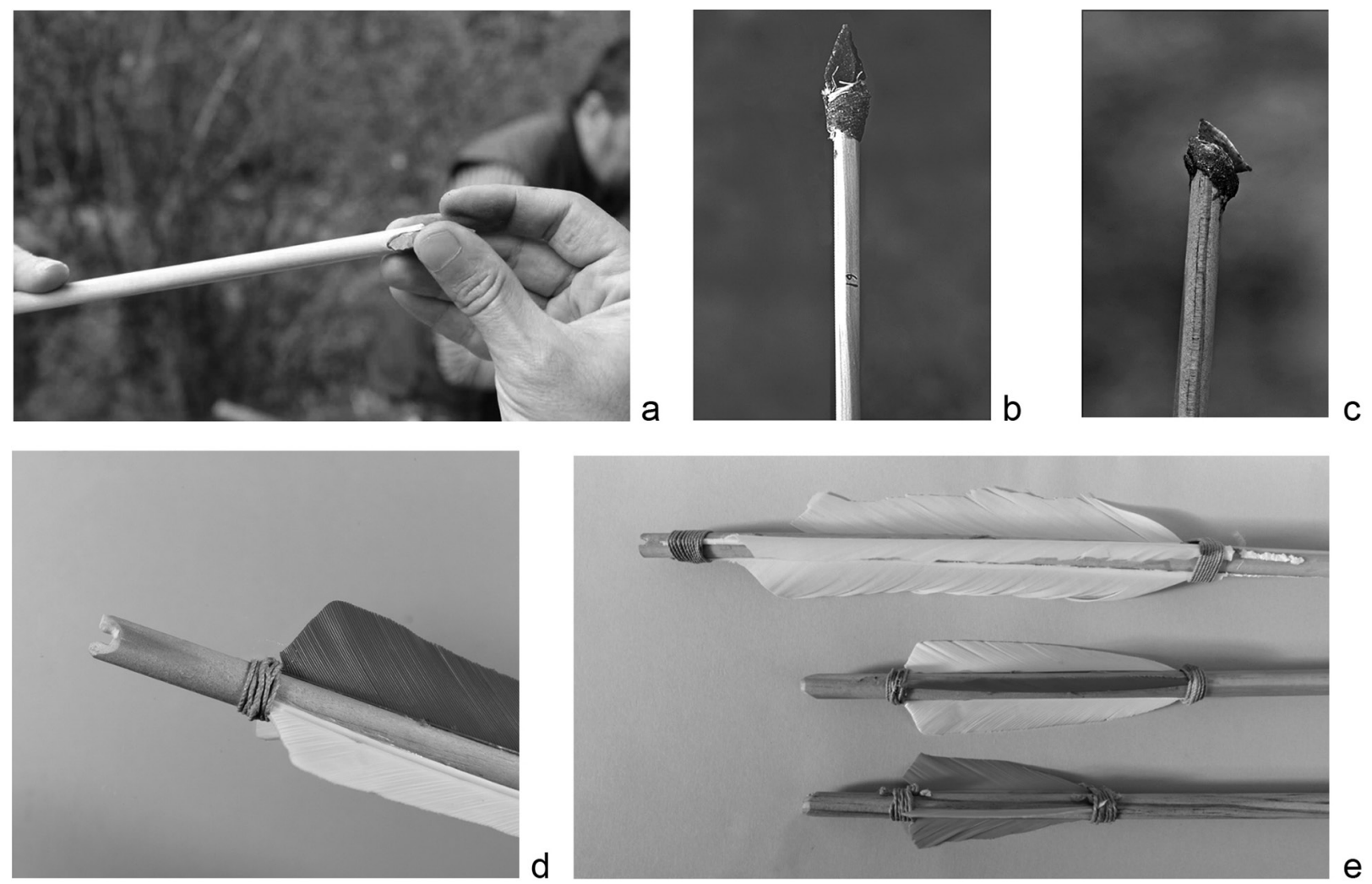

FIG. 5. Montaje de las flechas. en el paraje de Luberri que, desde el casco urbano, conduce al cementerio del pueblo. La elección de e 

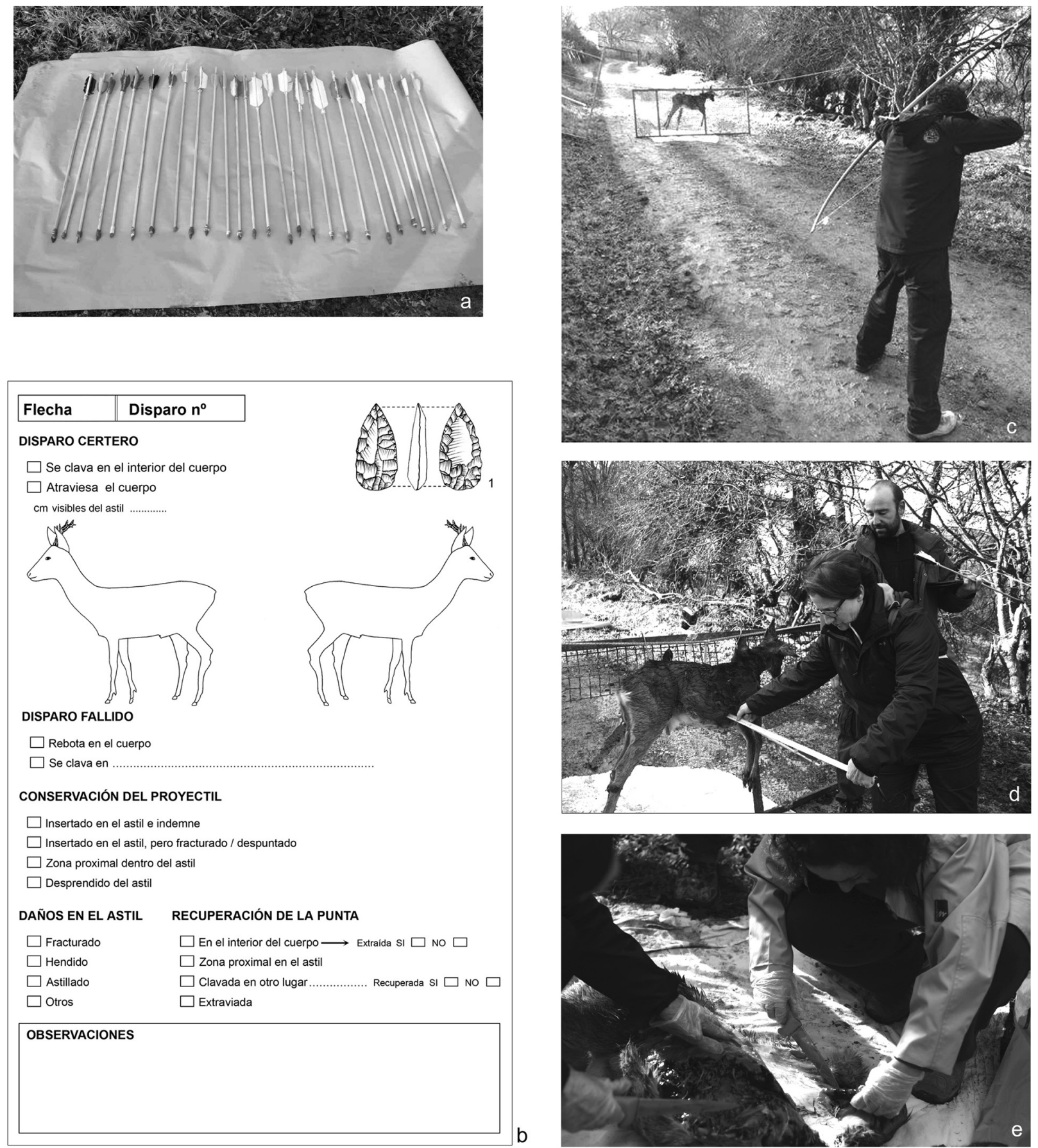

Fig. 6. Sesión de tiro experimental.

nuestro punto de tiro respondió a motivos logísticos y operativos, con el fin de que el desarrollo de los disparos se realizara con el máximo control y rigor. En este sentido, las características del emplazamiento, una suave pendiente, muy despejada, permitían en principio que en el caso de disparos fallidos en el espacio circundante, un suelo cubierto con hierba, las puntas pudieran recobrarse con más facilidad. 
Las flechas se transportaron con mucho cuidado para evitar roces o choques entre ellas, llegando al sitio en perfecto estado (Fig. 6a). El blanco, un ejemplar joven de corzo macho -Capreolus capreolus-, abatido la tarde anterior, no mostraba indicios de $r i$ gor mortis. De unos 20-22 kg de peso y sin eviscerar, fue suspendido de perfil mediante dos ganchos en un bastidor (Fig. 6c). Debajo del animal se colocó una tela, con la finalidad de recoger las armaduras o los fragmentos de las puntas que pudieran desgajarse. Se llevaron a cabo dos series de lanzamientos, con un arco simple fabricado artesanalmente en madera de tejo-Taxus baccata- y con una potencia de 40 a 45 libras, ejecutados por un avezado arquero, desde una distancia de $9 \mathrm{~m}$.

En la primera de ellas y con el objeto de comprobar la capacidad de resistencia de las puntas de flecha a la fractura en relación con su uso reiterado (Rodríguez Rellán, 2013: 290-291; Rodríguez Rellán et al., 2011: 1947), se planificó que seis flechas (n. ${ }^{\text {s }} 1,5,12,16,20$ y 27), representativas de las diferentes morfologías, se dispararan varias veces hasta que quedaran inservibles por su propia fractura o por daños irreversibles que se produjeran en la zona de enmangue o en los astiles. La segunda serie incluyó las 21 flechas restantes, con cada una de las cuales se realizó un solo tiro. Nada más disparar, se recuperaba la flecha antes del siguiente lanzamiento. Cuando los tiros resultaron errados, fuera del objetivo, las armaduras se buscaron en los alrededores.

El registro de campo consistió en cumplimentar sobre el terreno fichas individuales en papel de cada una de las flechas (Fig. 6b) que recogían la posición, profundidad, circunstancias e incidencias de cada disparo, además de las observaciones relativas a la recuperación y estado de conservación de las puntas y a los daños que sufrieron los astiles. El control in situ de los datos se complementó con una nutrida documentación gráfica, compuesta por fotografías digitales y la grabación de la dinámica general del ejercicio de tiro (Fig. 6d). Tras su conclusión, se realizó una disección del animal para recuperar las réplicas que habían quedado en el interior del corzo y tratar de comprobar posibles huellas de impacto en el esqueleto o en las partes blandas (Fig. 6e).

\subsection{Los resultados de las prácticas de tiro}

Con la información obtenida, registrada de modo sintético en la Fig. 7, es posible valorar el desarrollo de la experimentación. Se realizaron un total de 37 lanzamientos, de los cuales $23(62,16 \%)$ fueron certeros y $14(37,83 \%)$ fallidos, englobando entre estos últimos los que rebotaron en el cuerpo del animal y aquellos que impactaron en el terreno inmediato o en el bastidor (18,91\% respectivamente).

Conviene señalar, no obstante, que el empleo del número de tiros como unidad de cómputo introduce ciertas distorsiones en el recuento aplicado a las flechas propulsadas varias veces, de manera que tanto los disparos atinados como los errados resultan sobrestimados en dicha serie (Fig. 8). Pero, respecto a la reutilización y la recuperación de las flechas en época prehistórica, existen evidencias concretas en el excepcional hallazgo de la momia de Ötzi (Spindler, 1995: 181; Pernter et al., 2007), de modo que, teniendo en cuenta además el coste que conlleva la preparación de astiles y la fabricación de este tipo de proyectiles, no es aventurado suponer que fuese habitual la práctica de asaetear a varias presas o individuos con una misma flecha.

Si atendemos a la morfología de las puntas, todas las segmentiformes impactaron en el cuerpo del corzo, al igual que un $80 \%$ de las romboidales y casi las dos terceras partes de las armaduras pedunculadas con aletas incipientes $-62,5 \%$ - y de las foliformes -60\%-.

En la Fig. 9a se refleja la ubicación simulada de los impactos en el interior del animal. La mayor parte se sitúan por detrás de una de las extremidades anteriores (Fig. 9b) y concentrados en la caja torácica, cavidad donde se alojan órganos vitales -corazón, pulmones e hígado-. Como pudimos constatar con posterioridad, se produjeron colisiones contra dichas vísceras (Fig. 9d), lo que significa que, si se tratara de una presa viva, le hubieran causado heridas muy graves o mortales de necesidad, de modo que la muerte hubiese sobrevenido muy rápidamente. Una de las flechas incluso llegó a traspasar el cuerpo, desgarrándole la vejiga y sobresaliendo la punta por el lado opuesto (Fig. 9c). 


\begin{tabular}{|c|c|c|c|c|c|c|}
\hline Tipo punta & \multirow{2}{*}{$\begin{array}{c}\text { Flecha } \\
1\end{array}$} & \multicolumn{2}{|c|}{ Lanzam. } & \multirow{2}{*}{$\begin{array}{l}\text { Observaciones } \\
\text { se clava en el interior del cuerpo } \\
\text { rebota en el cuerpo }\end{array}$} & \multirow{2}{*}{$\begin{array}{l}\text { Recuperación punta } \\
\text { extraída completa dentro del astil } \\
\text { recuperada completa, pero desplazada dentro del astil }\end{array}$} & \multirow{2}{*}{$\begin{array}{l}\text { Astil } \\
\text { indemne } \\
\text { enmangue astillado }\end{array}$} \\
\hline \multirow{10}{*}{$\sqrt{1} / \int$} & & & $\begin{array}{l}\text { certero } \\
\text { fallido }\end{array}$ & & & \\
\hline & 2 & 1 & certero & se clava en el interior del cuerpo & desprendida del astil y recuperada completa dentro del cuerpo & indemne \\
\hline & 3 & 1 & fallido & impacta contra la tierra & desprendida del astil y extraviada & indemne \\
\hline & 4 & 1 & fallido & impacta contra la tierra & desprendida del astil y extraviada & enmangue astillado \\
\hline & 5 & $\begin{array}{l}1 \\
2 \\
3\end{array}$ & $\begin{array}{l}\text { certero } \\
\text { certero } \\
\text { certero }\end{array}$ & $\begin{array}{l}\text { se clava en el interior del cuerpo } \\
\text { se clava en el interior del cuerpo } \\
\text { se clava en el interior del cuerpo }\end{array}$ & $\begin{array}{l}\text { extraída completa dentro del astil } \\
\text { extraída completa dentro del astil } \\
\text { recuperada completa dentro del astil } \\
\end{array}$ & $\begin{array}{l}\text { indemne } \\
\text { indemne } \\
\text { enmangue astillado }\end{array}$ \\
\hline & 6 & 1 & certero & se clava en el interior del cuerpo & extraída completa dentro del astil & indemne \\
\hline & 7 & 1 & certero & se clava parcialmente en el cuerpo & desprendida completa del astil & enmangue astillado \\
\hline & 8 & 1 & certero & se clava en el interior del cuerpo & extraída completa dentro del astil & enmangue agrietado \\
\hline & 9 & 1 & certero & se clava en el interior del cuerpo & extraída completa dentro del astil & enmangue astillado \\
\hline & 10 & 1 & fallido & impacta contra la tierra & solamente se recupera la parte medial-proximal dentro del astil & enmangue agrietado \\
\hline \multirow{8}{*}{3} & 11 & 1 & fallido & impacta contra la tierra & recuperada incompleta y rota en varios fragmentos & enmangue astillado \\
\hline & 12 & $\begin{array}{l}1 \\
2\end{array}$ & $\begin{array}{l}\text { fallido } \\
\text { certero }\end{array}$ & $\begin{array}{l}\text { rebota en el cuerpo } \\
\text { se clava en el interior del cuerpo }\end{array}$ & $\begin{array}{l}\text { recuperada completa dentro del astil } \\
\text { desprendida del astil y recuperada completa dentro del cuerpo }\end{array}$ & $\begin{array}{l}\text { indemne, enmangue } \\
\text { desbaratado }\end{array}$ \\
\hline & 13 & 1 & certero & se clava en el interior del cuerpo & extraída completa dentro del astil & indemne \\
\hline & 14 & 1 & fallido & impacta contra la tierra & recuperada rota en varios fragmentos & fracturado \\
\hline & 15 & 1 & fallido & impacta contra el bastidor & solamente se recupera una parte del pedúnculo dentro del astil & fracturado \\
\hline & 16 & $\begin{array}{l}1 \\
2 \\
3 \\
4 \\
5\end{array}$ & $\begin{array}{l}\text { certero } \\
\text { fallido } \\
\text { certero } \\
\text { fallido } \\
\text { fallido }\end{array}$ & $\begin{array}{l}\text { se clava en el interior del cuerpo } \\
\text { rebota en el cuerpo } \\
\text { se clava en el interior del cuerpo } \\
\text { rebota en el cuerpo } \\
\text { rebota en el cuerpo }\end{array}$ & $\begin{array}{l}\text { extraída completa dentro del astil } \\
\text { recuperada completa dentro del astil } \\
\text { extraída completa dentro del astil } \\
\text { recuperada completa dentro del astil } \\
\text { recuperada completa dentro del astil }\end{array}$ & $\begin{array}{l}\text { indemne } \\
\text { indemne } \\
\text { indemne } \\
\text { indemne } \\
\text { enmangue fracturado }\end{array}$ \\
\hline & 17 & 1 & certero & atraviesa el cuerpo & extraída completa dentro del astil & enmangue hendido \\
\hline & 18 & 1 & certero & se clava en el interior del cuerpo & extraída completa dentro del astil & indemne \\
\hline \multirow{5}{*}{ 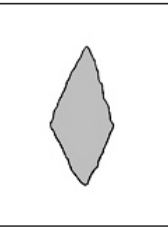 } & 19 & 1 & certero & se clava en el interior del cuerpo & desprendida del astil y recuperada completa dentro del cuerpo & indemne \\
\hline & 20 & $\begin{array}{l}1 \\
2\end{array}$ & $\begin{array}{l}\text { certero } \\
\text { fallido }\end{array}$ & $\begin{array}{l}\text { se clava en el interior del cuerpo } \\
\text { rebota en el cuerpo }\end{array}$ & $\begin{array}{l}\text { extraída completa dentro del astil } \\
\text { recuperada completa dentro del astil }\end{array}$ & $\begin{array}{l}\text { indemne } \\
\text { enmangue agrietado }\end{array}$ \\
\hline & 21 & 1 & fallido & impacta contra la tierra & solamente se recupera la parte medial-proximal dentro del astil & enmangue fracturado \\
\hline & 22 & 1 & certero & se clava en el interior del cuerpo & extraída completa dentro del astil & indemne \\
\hline & 23 & 1 & certero & se clava en el interior del cuerpo & extraída completa dentro del astil & indemne \\
\hline & 24 & 1 & certero & se clava en el interior del cuerpo & desprendida del astil y recuperada completa dentro del cuerpo & enmangue agrietado \\
\hline & 25 & 1 & certero & se clava parcialmente en el cuerpo & desprendida del astil & indemne \\
\hline & 26 & 1 & certero & se clava en el interior del cuerpo & extraída completa dentro del astil & enmangue astillado \\
\hline & 27 & \begin{tabular}{l|l} 
\\
2
\end{tabular} & $\begin{array}{l}\text { fallido } \\
\text { certero }\end{array}$ & $\begin{array}{l}\text { rebota en el cuerpo } \\
\text { se clava en el interior del cuerpo }\end{array}$ & $\begin{array}{l}\text { recuperada completa dentro del astil } \\
\text { extraída completa dentro del astil }\end{array}$ & $\begin{array}{l}\text { indemne } \\
\text { enmangue hendido }\end{array}$ \\
\hline
\end{tabular}

Fig. 7. Resumen de los resultados de la sesión de tiro.

De menor importancia podrían considerarse las cisuras originadas en los paquetes musculares situados junto a las vértebras cervicales y torácicas (Fig. 9e) y que poco hubieran afectado a la supervivencia del animal. La disección del animal nos permitió también comprobar la ausencia de puntas alojadas dentro de algún hueso, aunque se distinguió una perforación entre dos costillas que ocasionó una de las flechas (Fig. 9f).

La capacidad de penetración y, en consecuencia, la eficacia de las flechas para infligir daños se ha estimado teniendo en cuenta dos variables mensurables. A partir de las profundidades alcanzadas por cada flecha, que fueron medidas tras cada disparo certero (Fig. 6d), se hallaron las medias que corresponden a cada una de las diferentes morfologías. Otro factor es el ángulo del ápice, cuyo grado de influencia, no siempre determinante, ha sido comprobado en distintas experimentaciones con proyectiles (Odell y Cowan, 1986: 203; Rodríguez-Rellán et al., 2011: 1947).

Hemos calculado que entre $11-14 \mathrm{~cm}$ del extremo distal de las flechas se introdujeron en el 
interior del cuerpo del corzo, porciones suficientemente penetrantes en relación con la pequeña talla y escasa corpulencia de este mamífero. Cuanto más agudas eran las puntas, en este estudio las de morfología romboidal, con ángulos entre $43^{\circ}-55^{\circ}$, mayor fue su penetración en el animal, hasta $14,1 \mathrm{~cm}$ de media. Por contra, los ápices del resto de los tipos, con ángulos incluidos en un amplio y variable intervalo comprendido entre $52^{\circ}$ y $83^{\circ}$, tuvieron un alcance medio algo menor -foliformes, 12,5 $\mathrm{cm}$; segmentiformes, $11,6 \mathrm{~cm}$, y pedunculadas con aletas en apéndice, $10,4 \mathrm{~cm}-$.

Están excluidas de estos parámetros dos flechas $-n .^{\text {os }} 7$ y $25-$, que tan sólo agujerearon la piel del animal, clavándose parcialmente (Fig. 9g). Una menor potencia y velocidad de estas flechas, unidas a la resistencia al impacto que ofreció la piel del corzo, que lucía un denso pelaje de invierno, serían algunos de los factores que explicarían tal circunstancia.

Por otra parte, debido al alto porcentaje de puntas $-62 \%$ - que presentaban elevados ángulos apicales (Fig. 4), cabía la posibilidad, como han señalado ciertos autores, de que no penetraran en el blanco (Odell y Cowan, 1986: 203; Palomo y Gibaja, 2003: 185). Sin embargo, solamente cinco piezas $-n .{ }^{o s} 1,12,16,20$ y 27-, pertenecientes a la primera serie $y$, por tanto, disparadas varias veces, en alguno/os de los lanzamientos rebotaron en el cuerpo del corzo. Se han contabilizado siete disparos de este tipo que suponen un 18,91\% del total. Aunque no es posible establecer una relación directa entre el ángulo de las zonas activas puntuales y los tiros fallidos, sí se ha constatado que las armaduras

\begin{tabular}{|c|c|c|c|c|c|c|c|c|c|c|c|}
\hline \multirow[b]{2}{*}{ Disparos } & \multicolumn{5}{|c|}{ Primera serie } & \multicolumn{5}{|c|}{ Segunda serie } & \multirow[b]{2}{*}{ Total } \\
\hline & 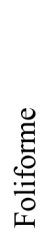 & 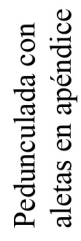 & 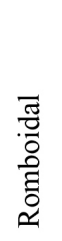 & 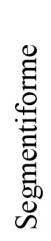 & 吾 & 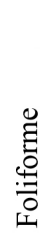 & 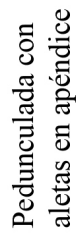 & 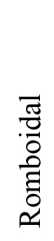 & 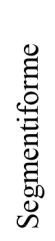 & 苞 & \\
\hline Certeros & 4 & 3 & 1 & 1 & 9 & 5 & 3 & 3 & 3 & 14 & $23(62,16 \%)$ \\
\hline Fallidos & 1 & 4 & 1 & 1 & 7 & 3 & 3 & 1 & - & 7 & $14(37,83 \%)$ \\
\hline
\end{tabular}

Fig. 8. Resultados de las series de disparos. con ángulos más grandes $-\mathrm{n} .^{\circ} 27\left(71^{\circ}\right)$ y n. ${ }^{\circ} 12$ $\left(81^{\circ}\right)$ - rebotaron en el primer disparo, si bien en el siguiente se clavaron en el interior. Las piezas restantes, tras un inicial tiro certero, fallaron después, con independencia del ángulo del ápice, probablemente porque el extremo distal estaba roto o mellado.

En cuanto al estado de conservación de las puntas, esto es, su capacidad de resistencia a la fractura, apreciamos diferencias según donde impactaron. Entre los tiros certeros, 14 armaduras $-51,85 \%$ - se recuperaron prácticamente completas -5 foliformes, 4 pedunculadas, 3 romboidales y 2 segmentiformes-, la mayoría dentro del astil (Fig. 10a-e). Enteras se hallaban también cuatro puntas más $-14,81 \%-$, cada una de ellas con una morfología distinta (Fig. 7), las cuales se separaron del vástago, recobrándose completas en el interior del corzo.

Los disparos errados, que chocaron contra el suelo o el bastidor, por su parte, causaron efectos dispares en un $25,92 \%$ de las piezas: la rotura en varios fragmentos y el desprendimiento de los cabezales líticos (Fig. 11, n. ${ }^{\text {os }} 2$ y 4), o daños irreparables en las puntas debido a severas fracturas, con la pérdida de la zona activa (Fig. 11, n. ${ }^{\text {os }} 1,3$ y 5). De estas piezas tan solo se conservaban las partes proximales-mediales, todavía insertadas en el astil (Fig. 10f y g). A pesar de una minuciosa búsqueda, no fue posible recuperar los fragmentos correspondientes a los extremos distales de cuatro de ellas y también se extraviaron otras dos puntas más, una fabricada en sílex de Bergerac $-7,40 \%$ del total-, de las cuales desconocemos su grado de integridad.

Los astiles sufrieron igualmente desperfectos que afectaron sobre todo a la zona del enmangue -en un $51,85 \%$ de los ejemplares- y se materializaron en su astillado (Fig. 10d y e) y en el agrietamiento o hendido de los fustes como consecuencia del contragolpe de las zonas proximales 

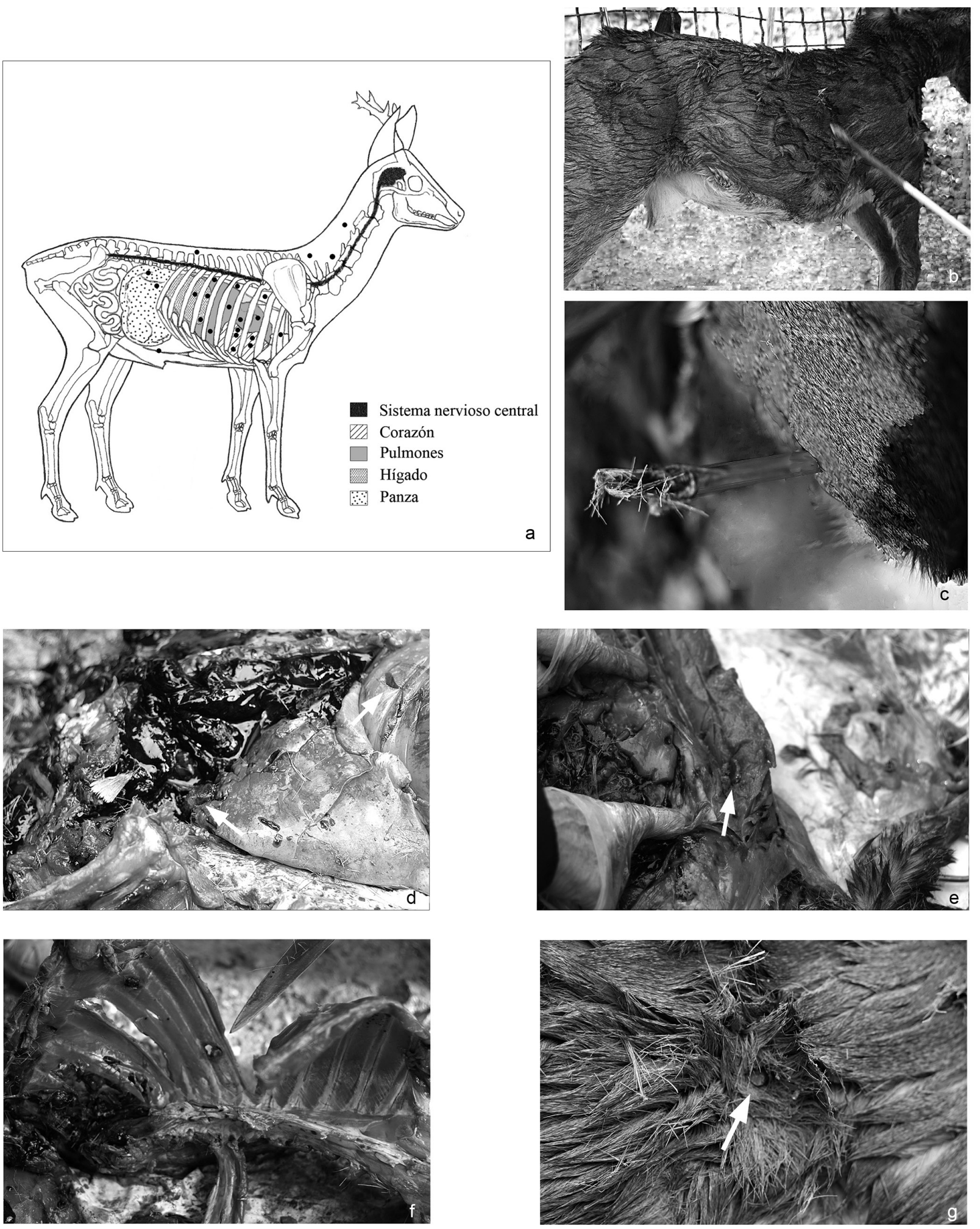

Fig. 9. Localización de los impactos de las puntas de flecha en el corzo. 

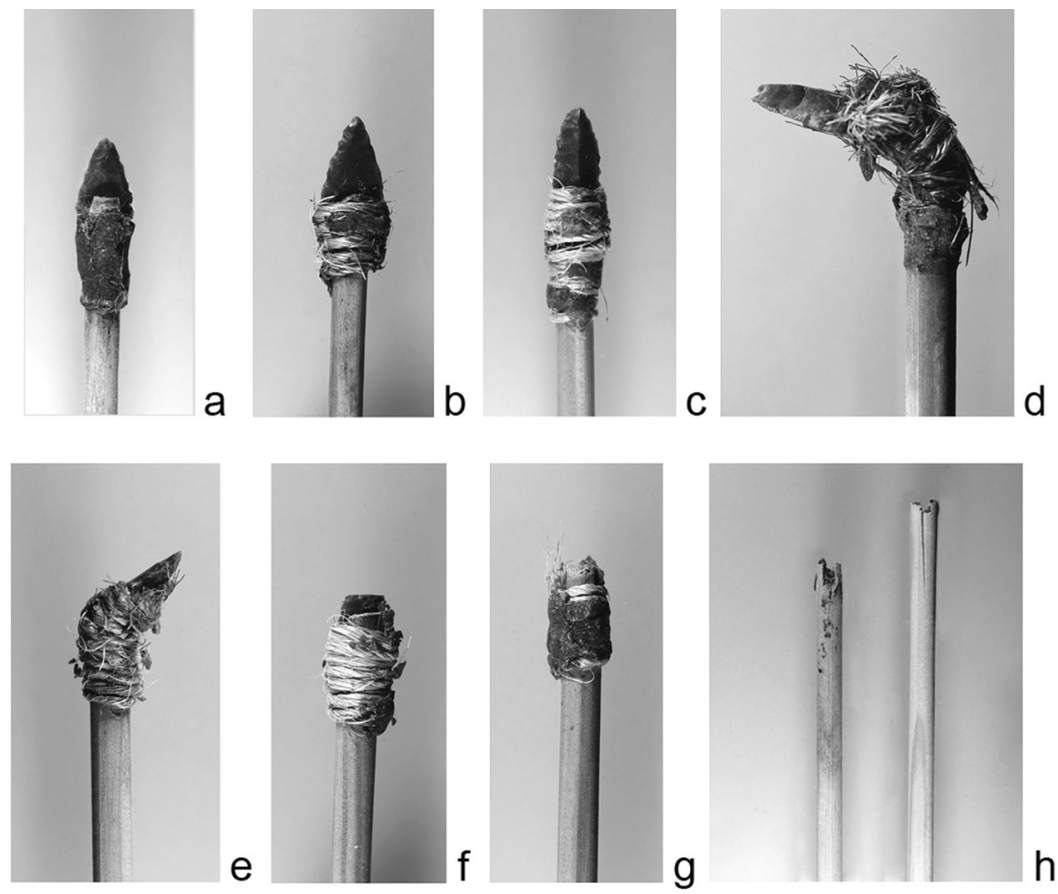

FIG. 10. Estados de conservación de algunas de las puntas dentro de los astiles y daños en los vástagos.

de las puntas en las ranuras donde se alojaban (Fig. 10h). Ello implicó que algo más de un tercio de las flechas quedasen inservibles para nuevos disparos. Tampoco pudieron reaprovecharse los vástagos fracturados $-14,81 \%$ - tras lanzamientos fallidos. Por el contrario, las flechas con los astiles indemnes suponen un $37,03 \%$ del total, de modo que hubieran podido reciclarse las varillas para futuros usos y prolongar su vida útil.

\section{Análisis funcional}

\subsection{Metodología}

Los medios técnicos empleados han sido una lupa binocular Carl Zeiss, con un objetivo de aumento entre $0.8 \mathrm{x}-5 \mathrm{x}$, y un tubo de dibujo acoplado que se utilizaron para observar y representar las zonas activas y las macrofracturas. La inspección a altos aumentos, en un rango medio comprendido entre 100x y 200x, se llevó a cabo con un microscopio metalográfico Nikon Epiphot y el registro fotográfico mediante una cámara digital, modelo Dino-Lite 7013/7023, adaptada indistintamente a los oculares de ambos aparatos ópticos.

Las réplicas experimentales se sometieron, tras un lavado inicial con agua y jabón neutro, y antes de ser insertadas en los astiles de las flechas, a un primer examen microscópico, de resultados negativos, para tratar de identificar otras posibles marcas de retoque, distintas a las ya observadas a simple vista y producidas por el compresor. Una vez utilizadas y extraídas de su enmangue, se limpiaron de nuevo del mismo modo, eliminándose los restos de adhesivo con un algodón impregnado en trementina mineral.

En el análisis riguroso del conjunto de huellas producto del uso hemos seguido las directrices propuestas por otros autores (Fischer et al., 1984; Fischer, 1990; Odell y Cowan, 1986; Dockall, 1997; Palomo y Gibaja, 2003; Rots y Plisson, 2014). La aplicación de estos planteamientos, adaptados a las particularidades de nuestra colección, nos ha permitido establecer unos criterios válidos para abordar de modo coherente la reconstrucción funcional de estas armas.

\subsection{Huellas de uso}

La presencia de estigmas indicativos del empleo de las puntas como proyectiles, si exceptuamos dos piezas extraviadas, se ha identificado en 16 armaduras -64\%-, de las 25 recuperadas (Fig. 12). El elevado índice porcentual obtenido podría obedecer a la conjunción de diversos factores como la precisión de los disparos, la velocidad y profundidad de penetración de las flechas y el grado de violencia de los impactos. En los lanzamientos certeros, estas variables, a su vez, estuvieron quizás condicionadas por las características del blanco utilizado, un joven corzo de pequeńa talla, y la relativamente próxima distancia de tiro. 
De dicho conjunto, un total de 11 ejemplares -44\%-, que acertaron en el objetivo, presentaban huellas diagnósticas de impacto combinadas: macrofracturas, micropulidos o estrías. Fracturas a escala macroscópica se detectaron también en otras cinco puntas $-20 \%-$, engastadas en flechas cuya trayectoria fue errada, y rotas por colisionar contra la tierra o contra un travesaño del bastidor. Por otra parte, es apreciable la proporción de armaduras con diversa morfología -36\% - sin rastros reconocibles, la práctica totalidad además se conservaban intactas (Fig. 13).

\subsubsection{Estigmas de impacto}

El análisis de los estigmas ha comenzado con el cotejo de las siluetas de las piezas antes y después de su uso. Se observan diversas incidencias, resultado de los efectos de las colisiones en las puntas, que varían según si los tiros fueron certeros o fallidos. Respecto a los primeros, produjeron, con independencia del morfotipo, la fractura de los ápices en un $44 \%$ de las piezas. La merma de muy pequeñas porciones de los extremos distales no impidió, sin embargo, la penetración en el blanco de las puntas de flecha, algunas de ellas incluso se lanzaron varias veces.

Una consecuencia positiva fue también el mantenimiento íntegro de aletas incipientes y pedúnculos en aquellas réplicas que estaban dotadas de los mismos. Las cuerdas del dispositivo de enmangue sobre las que se apoyaban las pequeñas aletas actuaron como elemento amortiguador durante los choques y los cajeados absorbieron las fuerzas de resistencia de las puntas, evitando el retroceso y choque de los pedúnculos en su interior.

Las secuelas de los disparos errados fueron mucho más intensas y evidentes, en relación directa con la contundencia de los impactos y conllevaron la inutilidad de las puntas. El tamaño estilizado de algunas armaduras, en concreto ciertas siluetas foliformes, propició que perdieran buena parte de la masa de la zona medial-distal (Fig. 11, no ${ }^{\text {os }} 1$ y 5 ), al igual que la presencia de largos pedúnculos favoreció su rotura en varios fragmentos debido a los contragolpes contra los astiles (Fig. 11, n. ${ }^{\text {os }} 2-4$ ).

\subsubsection{Huellas macroscópicas}

Son las más abundantes y se trata de los negativos que dejan las esquirlas que se desprenden de los ápices o los filos durante su flexión y rotura. En su formación han intervenido de manera determinante las propiedades físicas y mecánicas del sílex del Flysch en el que se fabricaron las armaduras, la violencia del choque y la resistencia de la zona activa a la fractura. Se han identificado en 15 puntas (60\%), principalmente en los extremos distales $(86,66 \%)$ y, en menor medida, en las partes mediales (13,33\%). Todos los tipos de puntas muestran estos saltados producto del impacto, si bien las piezas más numerosas afectadas por los mismos son las foliformes y pedunculadas con aletas en apéndice $(33,33 \%$ cada una de ellas), respecto a las morfologías romboidales o segmentiformes (16,66\% respectivamente).

Los dos primeros atributos considerados para su estudio son el número y posición de las melladuras generadas, registrándose una a una, tanto por piezas como en cada una de las caras de las zonas activas. En las puntas disparadas una sola vez, la comparación de los resultados permite apreciar cantidades de esquirlamientos más elevadas concentradas en las categorías romboidales y foliformes, aunque con porcentajes discretos $(31,74 \%$ y $30,15 \%)$, frente a la más limitada presencia de desconchados en las piezas con pedúnculo y aletas apenas esbozadas y segmentiformes, que ofrecen proporciones equilibradas que alcanzan el 19,04\%. Predomina la distribución bifacial de las macrofracturas, si bien se localizan en mayor cuantía en una de las caras, con más frecuencia en la ventral $(72,72 \%)$, configurando pequeñas agrupaciones compuestas por entre dos y seis melladuras (Fig. 16, n. ${ }^{\text {os }} 3$ y 4; Fig. 17, n.o 2, y Fig. 18, n. ${ }^{\text {os }} 2$ y 3 ).

En cuanto a las puntas utilizadas en varios tiros, se han observado dos diferentes fenómenos unifaciales detectados a partir del segundo o tercer lanzamiento: por un lado, una eliminación del ápice, acompañada de un numeroso amontonamiento de saltados en una de las caras, que le confieren un apariencia astillada (Fig. 16, n. ${ }^{\circ}$ 2) y, por otro, el incremento paulatino y notable del número de desconchados, de considerables dimensiones, en los 

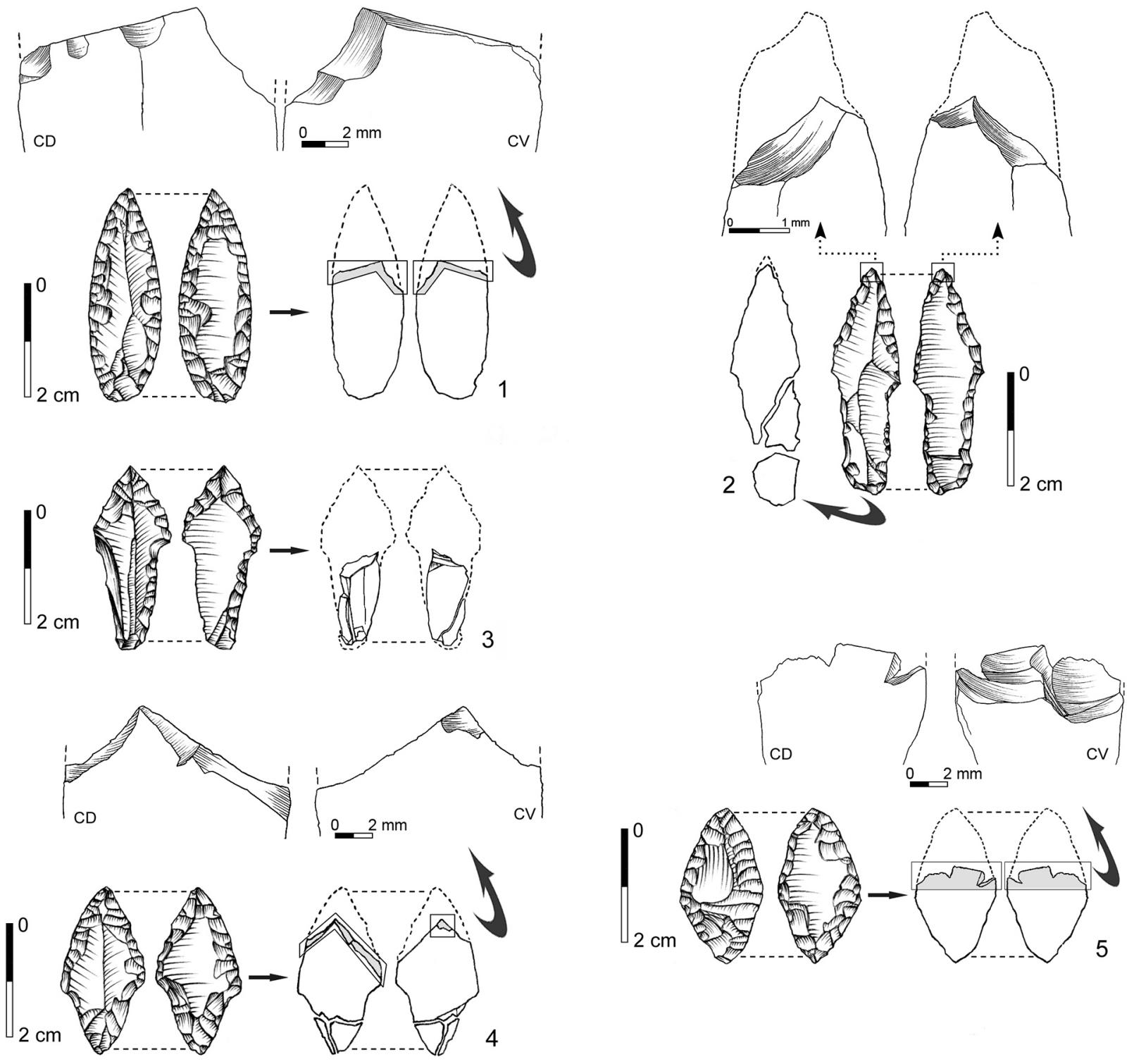

FIG. 11. Roturas y macrofracturas en las puntas $n^{\circ 5} 10,14,15,11$ y 21 tras disparos errados.

filos de alguna de las caras (Fig. 17, n. ${ }^{\circ}$ 3), alcanzando su mayor densidad en el cuarto o quinto disparo.

Con los datos obtenidos, sin embargo, podemos concluir que del análisis de estos atributos no es posible establecer patrones claros de inferencia funcional ya que en la cantidad de esquirlamientos originados en cada una de las puntas debieron influir variables, difícilmente mensurables, como la fuerza que impulsa la propulsión de las flechas, la solidez y modo de enmangue o la violencia del roce/choque de las armaduras.

Otros criterios clasificatorios seguidos para el control detallado de los desconchados macroscópicos se basan en diversos estudios y experimentaciones con réplicas de distintos tipos de proyectiles (Barton y Bergman, 1982; Fischer et al., 1984; González e Ibáñez, 1994; Dockall, 1997; Palomo y Gibaja, 2003), y son los siguientes: 


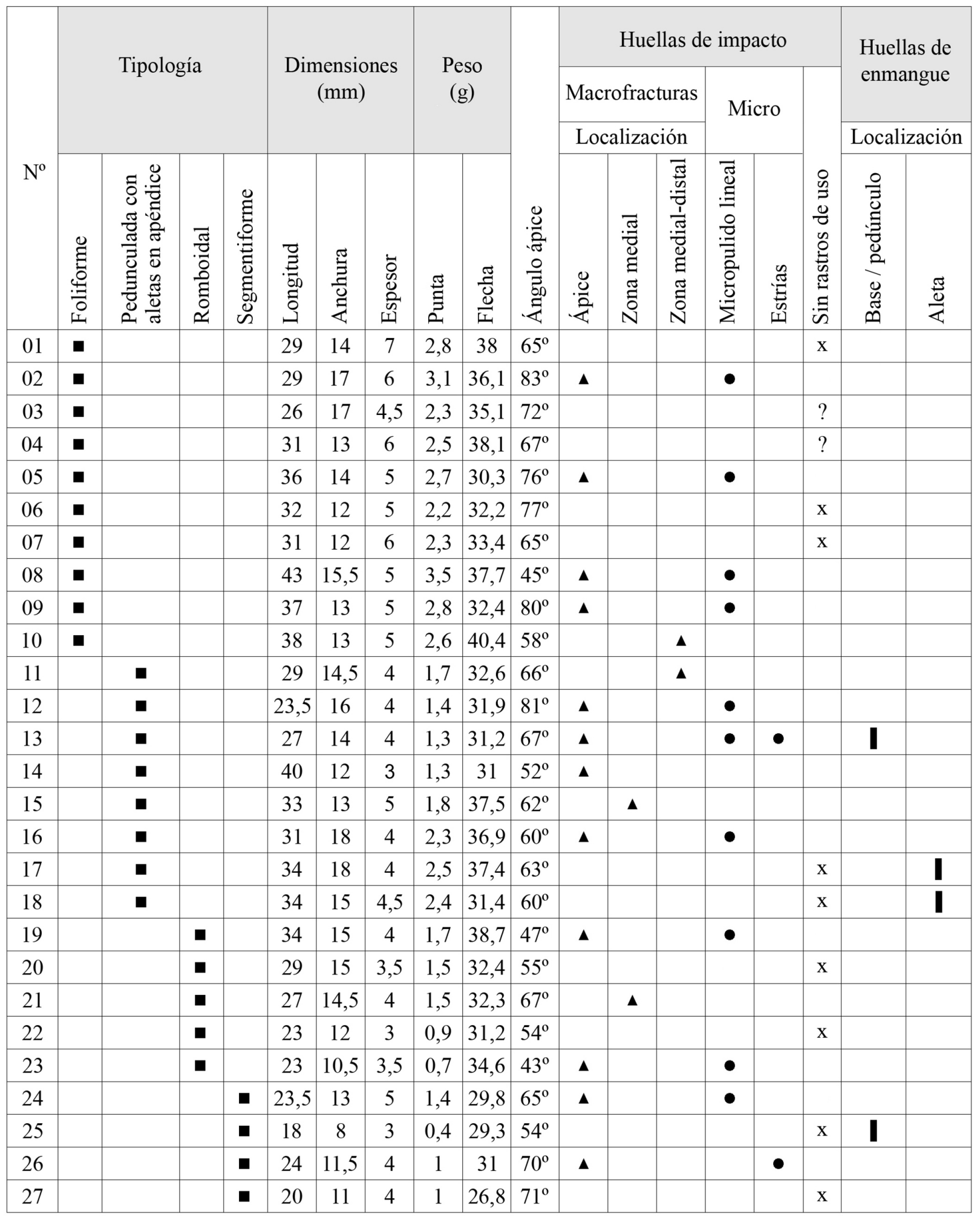

Fig. 12. Resultados del análisis traceológico. 


\begin{tabular}{|c|c|c|c|c|c|c|c|c|}
\hline \multirow[b]{4}{*}{ Morfotipos } & \multicolumn{8}{|c|}{ Puntas recuperadas (25) } \\
\hline & \multicolumn{4}{|c|}{ Tiros certeros } & \multicolumn{4}{|c|}{ Tiros errados } \\
\hline & \multicolumn{3}{|c|}{$\begin{array}{l}\text { Huellas de impacto } \\
\text { macro y micro }\end{array}$} & \multirow[b]{2}{*}{ 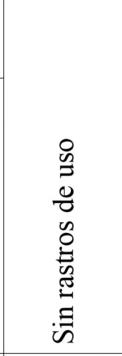 } & \multicolumn{3}{|c|}{$\begin{array}{c}\text { Huellas de impacto } \\
\text { macroscópicas }\end{array}$} & \multirow[b]{2}{*}{ 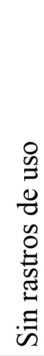 } \\
\hline & 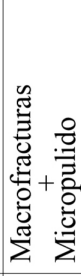 & 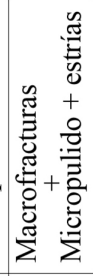 & 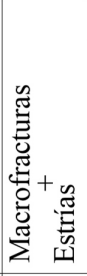 & & 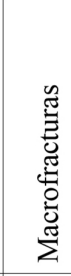 & 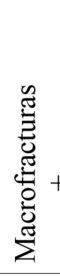 & 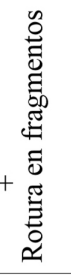 & \\
\hline Foliforme & 4 & - & - & 3 & 2 & & - & - \\
\hline $\begin{array}{l}\text { Pedunculada con } \\
\text { aletas en apéndice }\end{array}$ & 3 & - & - & 2 & - & & 3 & - \\
\hline Romboidal & 2 & - & - & 2 & - & & - & - \\
\hline Segmentiforme & - & 1 & 1 & 1 & - & & - & - \\
\hline Total & \multicolumn{3}{|c|}{$11 \rightarrow 44 \%$} & $9 \rightarrow 36 \%$ & \multicolumn{3}{|c|}{$5 \rightarrow 20 \%$} & 0 \\
\hline
\end{tabular}

FIG. 13. Indices de utilización.
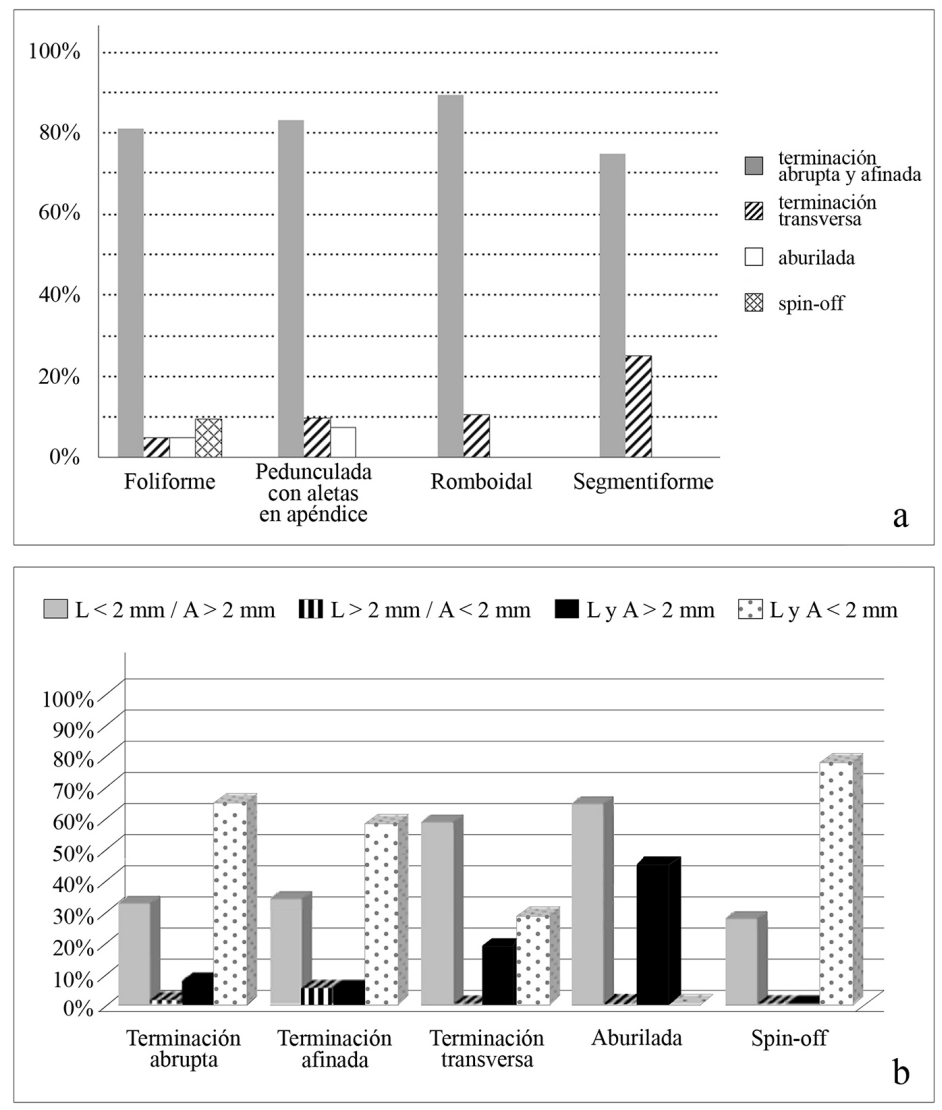

FIG. 14. Tipos y tamaños de las principales macrofracturas.
- Los modelos de macrofracturas establecidos en la literatura traceológica. Se incluyen tipos específicos como aburilados o burinoides; en charnela, que ostentan una lengüeta destacada y spin-off. Además de ellos, la mayor parte de las melladuras producidas por la flexión ocasionada en el momento del impacto se definen según sea la terminación de su parte distal, distinguiéndose tres variantes:

a) Afinada: los negativos describen una suave curvatura.

b) Abrupta: el desarrollo del negativo se interrumpe por un escalón.

c) Transversa: el negativo secciona perpendicularmente la zona afectada por la fractura.

- Tamaño: dimensiones de longitud y anchura máximas medidas en décimas de milímetro, estableciéndose dos módulos: inferior a $2 \mathrm{~mm}$ y superior a $2 \mathrm{~mm}$. La longitud es la distancia perpendicular desde el borde hasta el extremo distal de un desconchado y la anchura es la medida paralela al filo que existe entre las aristas laterales de una melladura.

- La disposición de los desconchados: aislada, alineada o superpuesta.

Respecto a los tipos de macrofracturas, se ha registrado en todas las variantes morfológicas de las puntas un predominio, en los extremos distales, de aquellos con terminación abrupta o afinada, alcanzando elevados porcentajes, comprendidos entre un 75\%-89,47\%, si se comparan con las proporciones del resto de desconchados, claramente minoritarias (Fig. 14a).

El análisis métrico de estas específicas melladuras evidencia el elevado índice que alcanzan los tamaños muy pequeños, con dimensiones menores a $2 \mathrm{~mm}$ 
tanto en longitud como en anchura. Esta importancia cuantitativa de los esquirlamientos muy cortos y estrechos se ha reflejado en una mayor proporción en los de terminación abrupta (60,25\%). Otro módulo registrado se caracteriza por notorias diferencias entre las magnitudes básicas medidas. Se trata de desconchados más anchos ( $>2 \mathrm{~mm}$ ) que el grupo anterior, aunque también de escasa largura (<2 mm), así lo confirman los equilibrados, pero nada desdeñables valores porcentuales constatados (30,76\%, las macrofracturas abruptas y $31,57 \%$, las afinadas). Por último, resta mencionar la escasa presencia de desconchados con longitudes y anchuras superiores a $2 \mathrm{~mm}$, si bien los ejemplos más significativos se hallan entre los de terminación transversa (14,28\%) (Fig. 14b).

Atendiendo a la sección observada en la inspección con lupa binocular, abundamos en lo ya apuntado acerca de la preponderancia, en todas las categorías formales, de una rotunda mayoría de las terminaciones abruptas -las proporciones más altas en piezas foliformes $(91,1 \%)$ y romboidales $(82,3 \%)$, mientras que en las armaduras pedunculares los porcentajes descienden al 76,4\% y en las segmentiformes al 66\%- frente a las afinadas, cuya representación es muy discreta, entre un 8,8\% y un 33\% (Fig. 15).

Las disposiciones identificadas se concretan en agrupaciones superpuestas (Fig. 17, n. ${ }^{\circ}$ ) que, en ocasiones, invaden las zonas inmediatas e internas de las caras de las puntas (Fig. 16, n. ${ }^{\text {os }} 2$ y 4 ) y alineaciones extendidas por los bordes conservados tras las roturas de los ápices (Fig. 16, n. ${ }^{\circ} 3$; Fig. 17, n. ${ }^{\circ}$ 3).

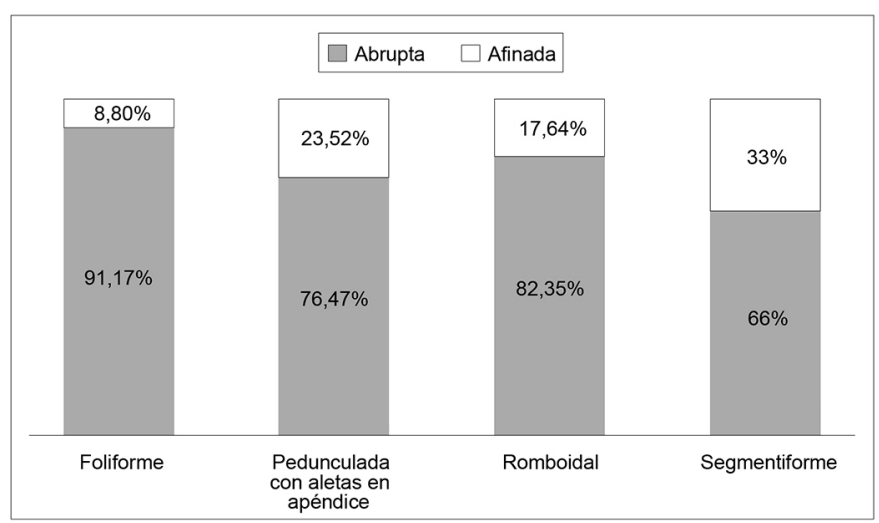

FIG. 15. Terminaciones abruptas y afinadas de las melladuras.
En cambio, el valor porcentual de las melladuras aisladas tan solo alcanza un $8,79 \%$.

Los esquirlamientos de terminación transversa, de limitada incidencia en el conjunto, están presentes en todas las morfologías, pero en pequeñas proporciones (Fig. 14a). Suponen un 26\% de los desconchados reconocidos en las armaduras segmentiformes, muestran frecuencias muy bajas $-10 \%$ - en las puntas romboidales y pedunculadas con aletas en apéndice y en las réplicas foliformes apenas superan el $5 \%$. Se caracterizan por un plano de rotura perpendicular al eje de simetría longitudinal de las puntas. Allí donde se produce abarca toda o la práctica totalidad de la anchura de las piezas. En nuestra experimentación se asocian a macrofracturas de terminaciones afinadas (Fig. 18, n. ${ }^{\circ} 1$ ) e incluso en un caso ha seccionado un desconchado previo de tipo aburilado. Estas relaciones han reforzado el limitado valor diagnóstico de las melladuras transversales. Sin embargo, resulta difícil distinguir estas fracturas de naturaleza macroscópica de aquellas que a menudo se observan en puntas prehistóricas y que bien pudieron ser producto de procesos naturales o fortuitos ocasionados en el transcurso de la vida útil de las armaduras o tras su abandono. Por esta razón, planteamos la necesidad de que en los estudios funcionales se consignen y analicen en relación con otros estigmas de impacto, lo cual ayudará a interpretarlas como fracturas de uso.

Concluimos este apartado aludiendo a otros tipos de macrofracturas. Las morfologías aburiladas o burinoides son muy escasas y equivalen al 4,54\% del total de las melladuras. Se han originado en dos puntas, una foliforme y otra pedunculada con aletas incipientes (Fig. 11, n. ${ }^{\text {os }} 1$ y 4). Son fracturas con tamaños comprendidos en un intervalo entre $>3 \mathrm{~mm}$ y $6 \mathrm{~mm}$ de anchura (vid. Fig. 14b), localizadas en las zonas mediales-distales y que afectan a los laterales de las piezas. Se ha identificado también un spin-off o rotura transversa que secciona perpendicularmente una buena parte del extremo distal de una armadura foliforme y lleva asociados los negativos de pequeńos desconchados 
$(<2 \mathrm{~mm})$ de terminaciones abrupta y afinada, originados a partir del plano de fractura y que tienen un desarrollo unifacial (Fig. 11, n. ${ }^{\circ} 1$ ).

\subsubsection{Huellas microscópicas}

Constituyen las huellas más significativas para reconstruir la utilidad de las puntas como proyectiles e implican alteraciones microscópicas de la superficie original del sílex. Hemos identificado micropulidos lineales en un $40 \%$ de la colección experimental y solamente estrías en un $8 \%$ de las puntas. Los primeros son finas bandas de pulido brillante, de variada longitud, con una disposición lineal (Fig. 16b y d; Fig. 17b y c; Fig. 18a), en ocasiones doble (Fig. 16a; Fig. 17a) (Fischer et al., 1984: 32; Fig. 16), que pueden estar asociados a finas estrías (Fig. 18c).

La velocidad con la que se han clavado las flechas en el blanco, justo en el momento de la penetración, propicia un desplazamiento por la superficie de minúsculas esquirlas líticas desprendidas de los ápices y/o filos de las puntas. Durante esta fricción instantánea, el recorrido de dichas esquirlas, condicionado por la trayectoria de las flechas, determinará la direccionalidad de los micropulidos. Se han observado orientaciones paralelas y ligeramente oblicuas respecto al eje longitudinal de las piezas. Por otro lado, la mayor parte de los micropulidos se sitúan en las caras ventrales, en relativa cercanía a los ápices rotos, pero nunca parten de los bordes de las macrofracturas identificadas, y siempre en zonas lisas, sin retocar, circunstancia que ha favorecido su desarrollo. Este hecho nos lleva a aventurar la dificultad tanto para que se produzcan como para detectarlos en armaduras fabricadas con retoque plano cubriente o invasor, que se caracterizan por estar configuradas por superficies irregulares.

A través del microscopio óptico hemos reconocido también, en una punta segmentiforme, una nítida estría (Fig. 18d). Su apariencia visual es la de un trazo linear brillante largo y angosto, excavado en la superficie del sílex, con una dirección algo oblicua en relación con el eje vertical de la pieza. La observación a 200 y 400 aumentos ha permitido apreciar que el fondo es rugoso y los bordes que la definen irregulares, fruto del arrastre y extracción de cristales de la estructura del sílex. Esta percepción nos permite atribuir el origen de la hendidura a un proceso de formación mecánico, en el que la superficie silícea debió de ofrecer resistencia a la presión del roce generada por la intrusión de partículas líticas que rayaron la superficie y provocaron la pérdida de materia.

\subsubsection{Huellas de enmangue}

Los diferentes modos de configurar las zonas proximales -bases apuntadas o redondeadas, acondicionamiento de pedúnculos- tuvieron por finalidad mejorar la inserción de las armaduras como cabezales de las flechas, con su eje de simetría longitudinal dispuesto paralelamente al del astil. Este sistema aseguró un correcto balance de las flechas y se aplicó a todas las puntas excepto a un ejemplar segmentiforme $-n .^{\circ} 25-$, que se engastó con una orientación de su eje tecnológico oblicua al eje del vástago, pero no resultó tan eficaz porque el proyectil no alcanzó una penetración suficiente, tan solo perforó la piel del animal, clavándose parcialmente.

Las huellas de enmangue registradas son muy escasas. Desde el punto de vista macroscópico, únicamente se han detectado roturas múltiples pedunculares, con planos de fractura originados por flexiones producidas unos milímetros después de las muescas desde donde arrancaban las espigas. Ello fue debido a que en el momento del impacto estas puntas no pudieron retroceder en el dispositivo del enmangue al hallarse más firmemente fijadas al astil que el resto de las armaduras. En las diferentes partes basales del resto de las puntas, la mayoría apuntadas, tampoco se apreciaron desconchados asociados a posibles contragolpes contra el fondo de los cajeados en las que se hallaban engastadas.

La observación microscópica meticulosa a la que se han sometido cada una de las réplicas ha permitido reconocer abrasiones o micropulidos difusos en filos (Fig. 19, n. ${ }^{\text {os }} 1-2$ ) y aristas de los retoques de zonas proximales y pedúnculos (Fig. 19, n. ${ }^{\text {os }} 3-4$ ) (Gutiérrez, 1996: 58; Lammers-Keijsers et al., 2014: 464). La falta de estigmas o su limitado desarrollo podrían justificarse porque el adhesivo empleado fijó las piezas, 

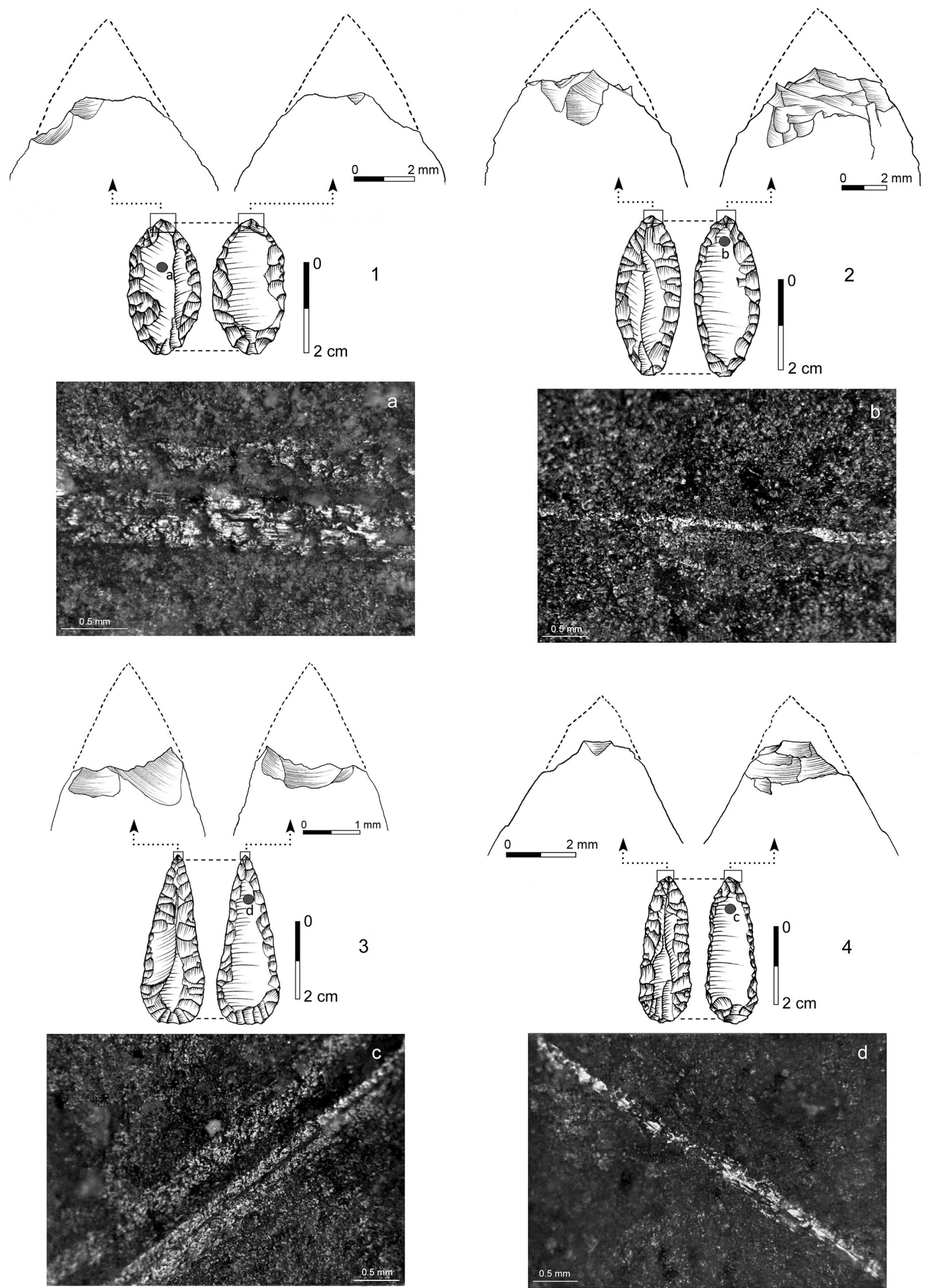

FIG. 16. Estigmas macroscópicos y microscópicos en las puntas n. 2, 5, 8 y 9; fotografías: a (200X); b-d (100X). 

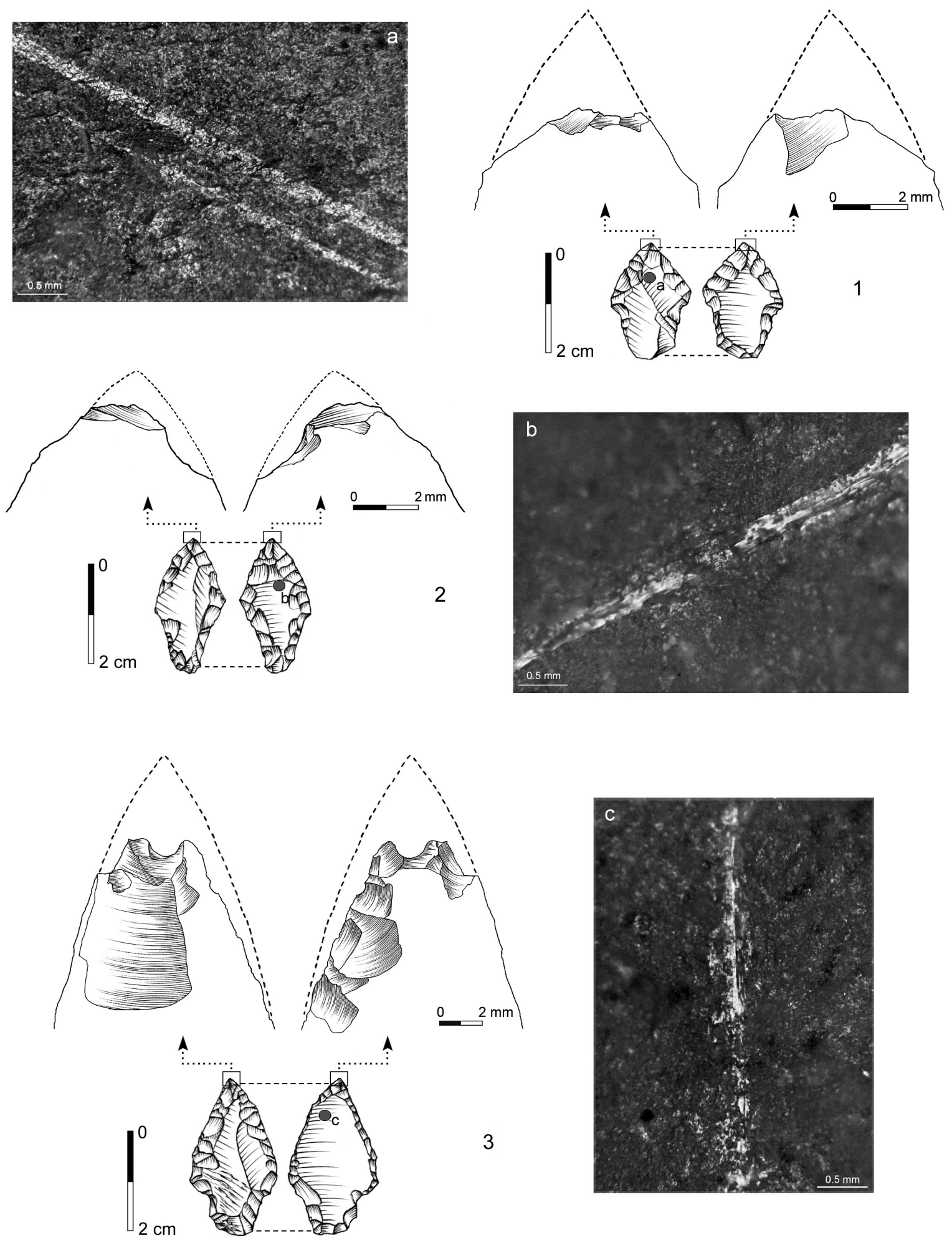

Fig. 17. Huellas de impacto en las puntas n. ${ }^{o s} 12,13$ y 16; fotografías a 100X. 
impidiendo la fricción contra la madera del vástago o al menos la mitigó en los casos en los que las puntas se desplazaron o desprendieron del engarce tras los disparos.

\section{Discusión final}

Los resultados obtenidos del análisis traceológico de la colección experimental evidencian una clara adecuación entre la forma de las puntas y su función como proyectiles. Sin embargo, la diversidad de tipos no ha entrańado diferentes comportamientos balísticos, y tampoco hemos constatado una correlación entre cada variante morfológica y rastros funcionales específicos, todos los formatos presentan semejantes estigmas de impacto (Lammers-Keijsers et al., 2014: 462-463). El ángulo de los ápices y la variabilidad tipométrica de la muestra sí influyeron en la penetrabilidad y eficacia de las puntas, que se reforzó en los proyectiles más aguzados y en las formas más alargadas al disponer de bordes cortantes laterales de mayor longitud que complementaban a las zonas activas puntuales. Además, los espesores bastante homogéneos de las zonas proximales de las diferentes puntas facilitaron su adaptación al sistema de enmangue y que las armaduras se insertaran centradas y ajustadas a las extremidades de los astiles.

Por otra parte, la fragilidad propia de estas armaduras, en algunas piezas incrementada por su estilización, es el caso de ciertas foliformes, o por estar dotadas de pedúnculos desarrollados constituyen variables que intervinieron en el grado de fracturación de las mismas y repercutieron negativamente en el rendimiento funcional de algunas de las puntas. Pero el factor decisivo no solo en la formación de huellas funcionales sino también en la integridad y rotura de las puntas es la violencia y el punto del impacto. En efecto, una punta sufre un intenso estrés cuando colisiona de este modo contra una materia dura -atraviesa densas masas musculares, se estrella en un hueso, contra tierra apelmazada, un tronco de un árbol, etc.-, propiciando su fragmentación.

El hecho llamativo, sin embargo, de que la mayor parte de las puntas disparadas se conserven prácticamente completas pudo deberse a dos factores: a) las puntas no se clavaron en huesos y b) el sistema y solidez del enmangue. La inserción de las puntas fue firme, pero el adhesivo empleado resultó quebradizo y no demasiado resistente porque en el momento del impacto se cuarteó y desprendió, casi en su totalidad en numerosas puntas, lo cual pudo influir en que ciertas ligaduras se destensaran, favoreciendo la separación de algunas armaduras del astil y que, en consecuencia, apenas sufrieran daños. Este modo de enmangue propició también que la mayor parte de las puntas permanecieran fijadas al astil sin fracturarse (Rots y Plisson, 2014: 156; Lammers-Keijsers, 2014: 463).

Las huellas diagnósticas producto del impacto, útiles para la identificación funcional como proyectiles de las puntas, son de naturaleza macroscópica, los desconchados, y microscópica, los pulidos lineales y las estrías, si bien no podemos proponer un patrón general taxativo, por el limitado número de piezas que componen la colección experimental.

Todas las puntas, en el momento del choque, experimentaron una tensión interna como respuesta a fuerzas de compresión y flexión, pero el origen de las macrofracturas estuvo condicionado por el propio proceso de fracturación -ubicación y tamaño del área de contacto, inicio y propagación de los desconchados- y por la resistencia mecánica que ofreció la materia prima silícea del Flysch. Las morfologías apuntadas de las zonas activas de las armaduras debieron sufrir un traumatismo frontal que en la mayoría de los casos no es proporcional a los exiguos daños registrados, que se concretan en el esquirlamiento y la eliminación de tan solo una mínima parte de los ápices de un buen número de puntas, siendo aquellas más agudas las que se han desconchado con más facilidad (Odell y Cowan, 1986: 203-204).

El mellado se ha materializado tanto en el escaso número de macrofracturas, cuya cantidad se incrementó cuando el uso de las puntas de flecha fue continuado (Figs. 15, n.o 2 y 16, n.o 3), como en el limitado grado de destrucción de los ápices. Se distinguen a simple vista de los retoques de las piezas, pero los prototipos morfológicos que 

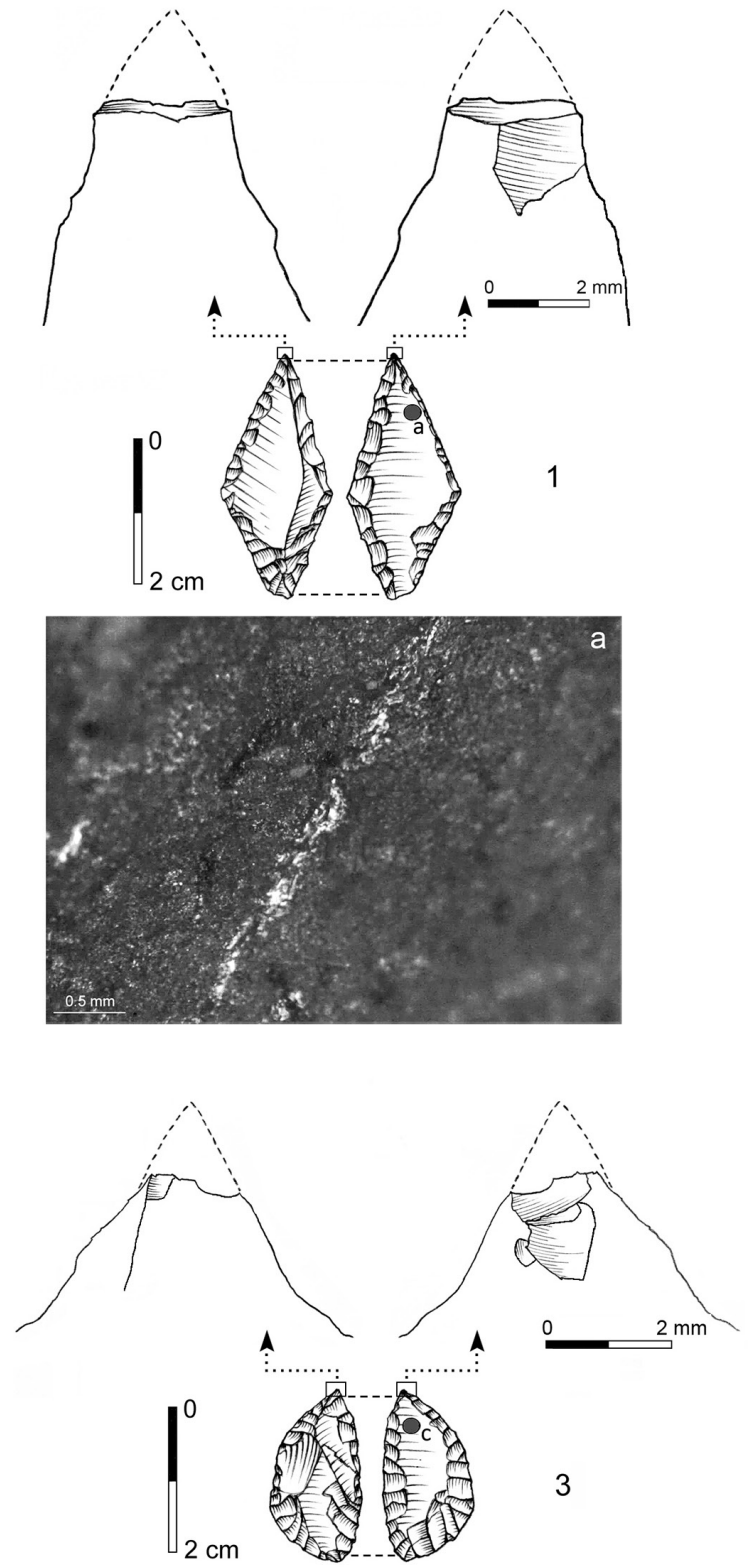

3

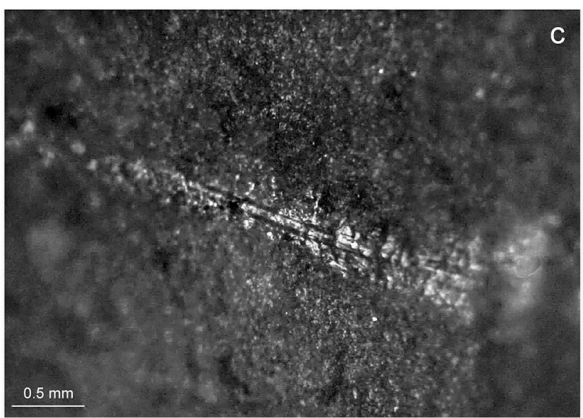

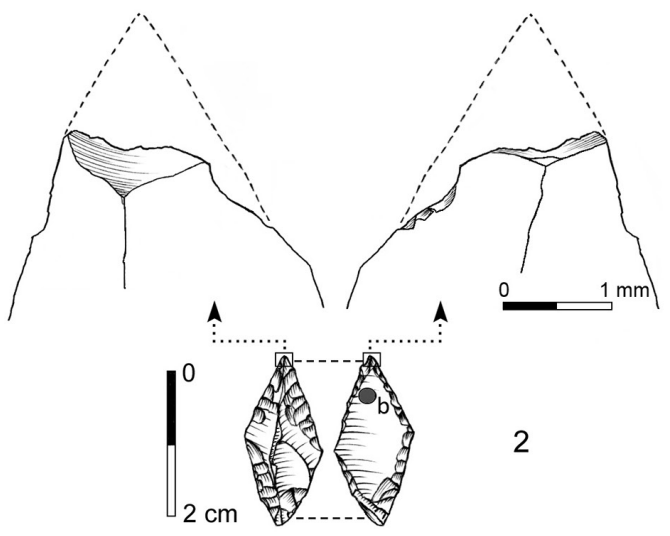
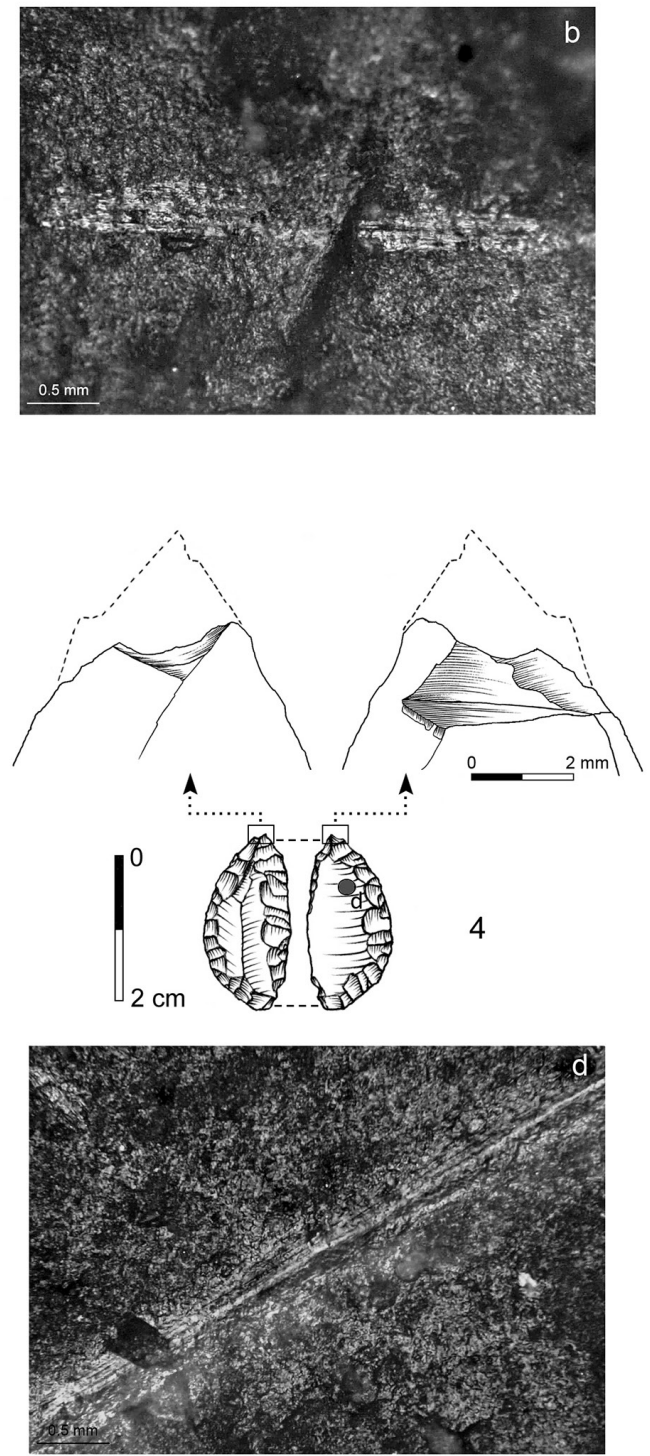

Fig. 18. Trazas de uso como proyectil de las puntas n. ${ }^{o s} 19,23,24$ y 26; fotografías a 100X. 
se consideran diagnósticos del uso de una punta como proyectil apenas se han identificado, en nuestro caso dominan los esquirlamientos agrupados, con una disposición bifacial y terminaciones abruptas (Odell y Cowan, 1986: 200 y 204). Suelen aparecer combinados con melladuras de terminación afinada o transversa (Palomo y Gibaja, 2003: 200). En general, presentan tamańos muy pequeńos que tampoco pueden equipararse a los frecuentes estándares dimensionales -superiores a $2 \mathrm{~mm}$ - registrados en otros estudios de huellas de uso. Como se acaba de señalar, también se han consignado, pero en menor medida, fracturas en las zonas mesiales y medial-distales de diversas puntas. Pertenecen a la variante burinoide, generada por una flexión oblicua axial y tienen un desarrollo longitudinal.

A diferencia de otros análisis traceológicos $(\mathrm{Pa}-$ lomo y Gibaja, 2002: 245; 2003: 201) no se han observado macrofracturas en otras partes que definen determinadas morfologías como las aletas. En nuestro caso, podría justificarse porque al ser tan poco protuberantes quedaron parcialmente protegidas por las ataduras del enmangue, sobre las que se apoyaban, que debieron de amortiguar los choques y mitigar los rozamientos. Ni siquiera las aletas que conferían una silueta asimétrica a algunas de las armaduras sufrieron daño alguno. Y tampoco la extracción de las flechas tras cada disparo conllevó ningún tipo de rotura.

Los indicios sobre la percusión lanzada aportados por las macrofracturas se han complementado y confirmado con la presencia de estigmas microscópicos. A los micropulidos lineales y a las escasas estrías identificadas les otorgamos una gran fiabilidad para interpretarlas como resultado del uso de las armaduras como proyectiles. Además la disposición que muestran estas huellas permite inferir la posición de las puntas en el extremo superior del astil.

Sin embargo, no siempre los lanzamientos de las puntas, incluso en los casos reiterados, generaron trazas de impacto reconocibles o provocaron que alguna de sus partes se fracturase. Prueba de ello es que, de 25 puntas recuperadas, un $36 \%$ no sufrió ningún tipo de daño, mostrando

(C) Universidad de Salamanca su resistencia a los impactos, ni se detectaron alteraciones microscópicas en la superficie silícea. Esta circunstancia, constatada por otros analistas (Palomo y Gibaja, 2003: 200), tiene implicaciones funcionales a la hora de realizar cómputos de índices de utilización de armaduras en colecciones arqueológicas, ya que las piezas carentes de huellas podrían interpretarse como puntas que se abandonaron o se depositaron intencionalmente sin llegar a utilizarse, cuando quizás fueron efectivamente usadas. En el estado actual del conocimiento, esta cuestión dista de ser resuelta.

Se ha registrado una frecuencia de uso relativamente alta $-64 \%$ - ya que más de la mitad de las piezas de la colección experimental conservaban huellas que permitían reconstruir su utilización como proyectiles. Este índice de empleo es el reflejo estadístico válido de una muestra que consideramos numéricamente representativa, pero resulta complicado compararlo con los obtenidos en otros estudios similares porque estos son escasos. Se añaden otros inconvenientes relativos a que las pocas experimentaciones con armaduras de proyectil líticas publicadas, en ningún caso contemporáneas, están dedicadas a morfologías diferentes a las que nos ocupan, el número de efectivos es muy diverso de unos a otros análisis, las réplicas utilizadas responden a prototipos procedentes de variados contextos arqueológicos y ámbitos geográficos y también son distintos los métodos de observación aplicados para detectar estigmas funcionales (Fischer et al., 1984; Fischer, 1990; Odell y Cowan, 1986).

La única referencia comparativa es el programa experimental desarrollado para el estudio de las puntas de flecha de pedúnculo y aletas recuperadas en el hipogeo de la Costa de can Martorell (Barcelona), pero tan solo es posible cotejar el número de puntas afectadas por macrofracturas, que en este caso se cifra en un 50\% de la colección (Palomo y Gibaja, 2002: 246). La confrontación de nuestros resultados indica que el porcentaje de puntas con huellas macroscópicas consignado en este estudio $-64 \%$ - es elevado respecto a las variables proporciones obtenidas en distintas experimentaciones, que varían entre un 40\% (Fischer et al., 1984: 25; 

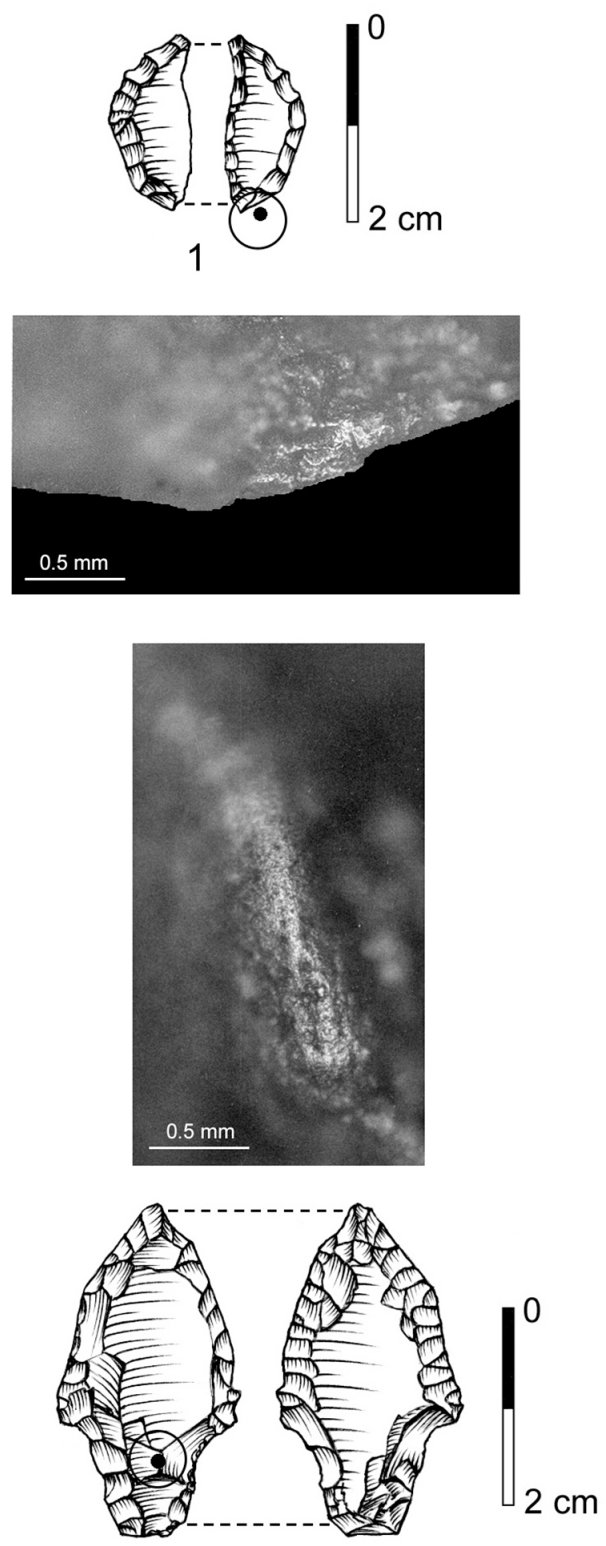

3
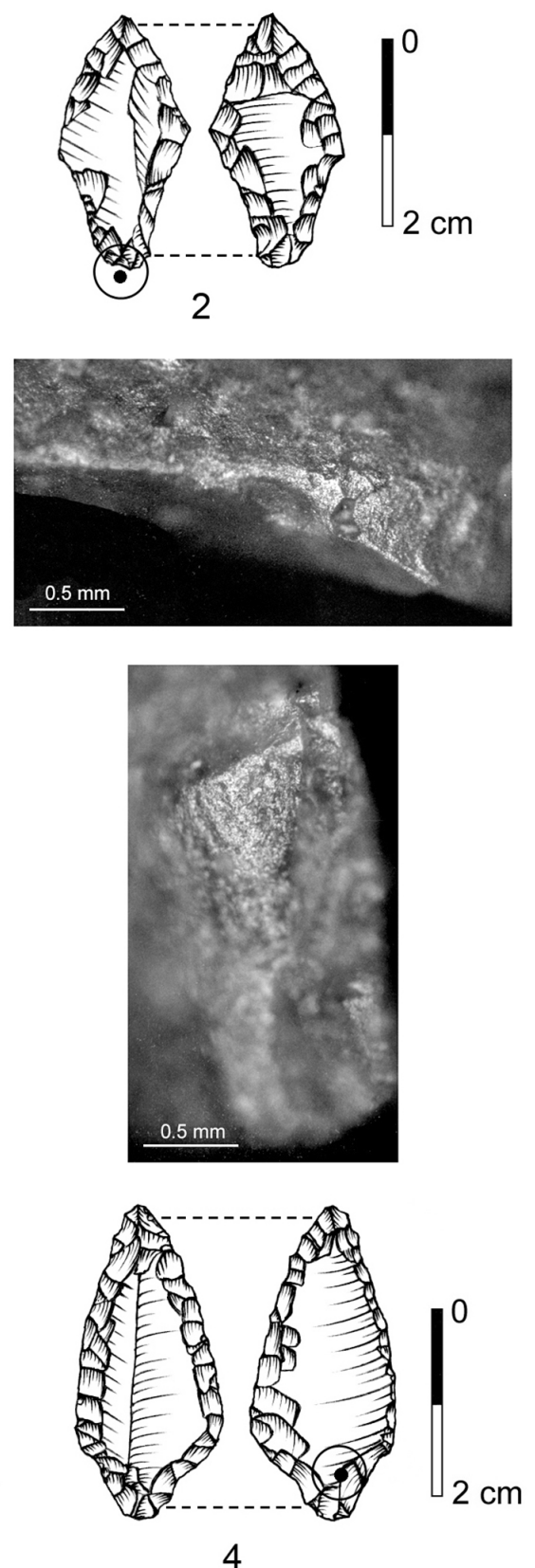

4

Fig. 19. Huellas microscópicas de enmangue en las puntas n. ${ }^{o s} 25,13,17$ y 18; fotografías a $100 x$.

Fischer, 1990: 31) y casi un 100\% (Odell y Cowan, 1986: 204). En cuanto a los estigmas microscópicos, en nuestras armaduras se registraron con una menor frecuencia $-44 \%$-, en relación con el valor medio $-60 \%$ - alcanzado en otros proyectiles experimentales (Fischer et al., 1984: 33).
Por otra parte, los datos extraídos demuestran la capacidad penetrante de las armaduras para infligir en el animal potenciales lesiones o heridas, de distinto alcance letal, aunque hubiera sido conveniente efectuar lanzamientos a diferentes distancias para confirmar con más rigor esta constatación. La eficacia de las penetraciones no ha ido pareja, en el caso de las réplicas con pequeñas prominencias laterales, de su retención en el interior del animal una vez clavadas, a excepción de un ejemplo -punta n. ${ }^{\circ} 12-$. Las características de estas partes de las puntas y el modo de quedar protegidas por el sistema de enmangue dificultaron que cumplieran con el objetivo funcional para el que quizás fueron diseñadas.

La extracción de las flechas provocó que algunas de las puntas se desprendieran y recuperaran dentro del corzo, hincadas en las partes blandas y paquetes musculares, en óptimas condiciones para ser recicladas en futuros usos. Esta circunstancia explicaría parcialmente el registro de armaduras en ámbitos domésticos, al llegar alojadas en presas enteras cobradas durante las

partidas de caza o en las porciones resultantes del despiece y transporte selectivo a los hábitats. Su presencia entre los restos óseos humanos hallados en depósitos funerarios se justificaría porque pudieron estar incrustadas en vísceras o tejidos de individuos en el momento de ser inhumados. 
Sugieren también los datos la posibilidad de reutilización de al menos un tercio de los proyectiles $-36 \%-$, plenamente operativos porque se recobraron intactos bien insertados o desprendidos del astil. Este porcentaje podría incrementarse hasta el $76 \%$ si sumásemos las piezas con mínimas roturas apicales que probablemente hubieran podido volver a ser utilizadas, con más garantía, tras una reparación para su afilado. Esta posible continuidad del uso conllevaría una prolongación de su vida útil con implicaciones funcionales que pudieran ser un reflejo, aproximado que no fiel, de supuestas situaciones pretéritas de la realidad prehistórica.

Por último, la eficacia probada de algunas de las puntas y su capacidad de resistencia a la fractura han quedado demostradas incluso tras un uso más intenso. En efecto, aun siendo lanzadas en varios disparos reiterados -entre 2 y 5 -, se clavaron igualmente en el cuerpo del animal en uno o en varios de los intentos, conservando las armaduras su integridad. En estos casos, el abandono de las flechas se produjo por daños irreversibles en los astiles.

Puede concluirse que el programa experimental y el análisis traceológico aquí descritos, aunque de carácter preliminar, han permitido conocer el comportamiento de las puntas de retoque plano al ser utilizadas como proyectiles, en aspectos relativos a las huellas generadas y a su capacidad funcional. A partir de esta base, es posible abordar la reconstrucción del uso de armaduras prehistóricas, teniendo en cuenta dos premisas:

a. La aplicación de los criterios funcionales propuestos no es extrapolable al estudio de otras puntas de flecha sin que medie una contrastación pertinente (González e Ibáñez, 1994: 69).

b. La colección experimental de referencia no se puede equiparar en términos de comparación estricta con los modelos y conjuntos de piezas arqueológicas (Rots y Plisson, 2014: 163). En este sentido, el diagnóstico sobre su uso va a depender del estado de conservación de los materiales líticos, de la variedad silícea en la que se fabricaron y de la presencia de estigmas de impacto. Además, las posibilidades que nos ofrecen estas huellas de utilización en el proceso de inferencia funcional han de complementarse, para prevenir sobrevalorarlas, con la información contextual procedente del registro arqueológico, las referencias etnográficas y las aportaciones de otras analíticas.

Con todo, esperamos que los resultados expuestos promuevan en un futuro el desarrollo de nuevos estudios que amplíen la comprensión de la funcionalidad de este tipo de armas.

\section{Bibliografía}

Armendáriz, J. e Irigaray, S. (1993-1994): "Resumen de las excavaciones arqueológicas en el hipogeo del Longar (Viana, Navarra), 1991-1993", Trabajos de Arqueología Navarra, 11, pp. 270-275.

Armendáriz, J. e Irigaray, S. (1995): "Violencia y Muerte en la Prehistoria: El hipogeo del Longar", Revista de Arqueología, XVI, 168, pp. 16-29.

Armendáriz, J.; Irigaray, S. y Etxeberria, F. (1994): "New evidence of prehistoric arrow wounds in the Iberian Peninsula", International Journal of Osteoarchaeology, 4, pp. 215-222.

Barton, R. N. E. y Bergman, C. A. (1982): "Hunters at Hetgistbury: some evidence from experimental Archaeology", World Archaeology, 14 (2), pp. 238-242.

Beguiristain, M. A. (2007): "Memoria de excavación e inventario de materiales del dolmen de Aizibita (Cirauqui, Navarra)", Cuadernos de Arqueología de la Universidad de Navarra, 15, pp. 43-142.

Beguiristain, M. A. (2011): "Armas líticas en dólmenes navarros”. En VII Congreso General de Historia de Navarra. Príncipe de Viana, 253. Pamplona, vol. I, pp. 43-62.

Beguiristain, M. A. y Etxeberria, F. (1994): "Lesión craneal seguida de supervivencia en un individuo del dolmen de Aizibita (Cirauqui, Navarra)", Cuadernos de Arqueología de la Universidad de Navarra, 2, pp. 49-69.

Cattelain, P. (1997): "Hunting during the Upper Paleolithic: bow, spearthrower, or both?”. En KNECHT, H. (ed.): Projectile technology. New York, pp. 213-240.

Cava, A. (1984): "La industria lítica en los dólmenes del País Vasco Meridional”, Veleia, 1, pp. 51-145.

DockALL, J. E. (1997): "Wear traces and projectile impact: a review of the experimental and archaeological evidence", Journal of Field Archaeology, 24, pp. 321-331. 
Etxeberria, F. y Herrasti, L. (2007): "Los restos humanos del enterramiento de San Juan Ante Portam Latinam (Laguardia, Álava): caracterización de la muestra, tafonomía y paleopatología”. En Vegas, J. I. (dir.): San Juan Ante Portam Latinam. Una inhumación colectiva prehistórica en el valle medio del Ebro. Vitoria-Gasteiz: Diput. Foral Álava, pp. 159-280.

Etxeberria, F. y Vegas, J. I. (1988): “'Agresividad social o guerra? Durante el Neo-eneolítico en la cuenca media del valle del Ebro, a propósito de San Juan Ante Portam Latinam (Rioja Alavesa)", Munibe (Antropologia-Arkeologia), Supl. 6, pp. 105-112.

Fischer, A. (1990): "Hunting with flint-tipped arrows: results and experiencies from practical experiments". En Bonsall, C. (ed.): The Mesolithic in Europe (Third International Symposium, 1985). Edimburgh, pp. 29-39.

Fischer, A.; Hansen, P. V. y Rasmussen, P. (1984): "Macro and micro wear traces on lithic projectile points. Experimental results and prehistoric examples", Journal of Danish Archaeology, 3, pp. 19-46.

GonZÁlez, J. E. e IbáNEZ, J. J. (1994): Metodología de análisis funcional de instrumentos tallados en sílex. Cuadernos de Arqueología, 14. Bilbao: Univ. de Deusto.

Gutiérrez, C. (1996): Huellas de uso. Pautas de análisis experimental. Temas de Arqueología, n. ${ }^{\circ}$ 4. Foro, Arqueología, Proyectos y Publicaciones. Madrid.

Lammers-Keijsers, Y.; Verbaas, A.; Van Gijn, A. y Pomstra, D. (2014): "Arrowheads without traces: not used, perfect hit or excessive hafting material?". En Marreiros, J.; Bicho, N. y Gibaja, J. F. (eds.): International Conference on Use-Wear. Analysis (Faro, 2012). Cádiz, pp. 457-465.

Liesau, C.; Ríos, P.; Blasco, C. y Gómez, J. L. (2014): "Indicios de violencia en yacimientos de la región de Madrid en el marco del Calcolítico peninsular", Gladius, xxxiv, pp. 7-37.

Lombard, M. y Partager, J. (2008): "Hunting with Howiesons Poort segments: pilot experimental study and the functional interpretation of archaeological tools", Journal of Archaeological Science, 35 (9), pp. 2523-2531.

Márquez, B. (2007): "Estudio de huellas de uso realizado sobre materiales de San Juan Ante Portam Latinam (Laguardia, Álava)". En Vegas, J. I. (dir.): San Juan Ante Portam Latinam. Una inhumación colectiva prehistórica en el valle medio del Ebro. Vitoria-Gasteiz: Diput. Foral Álava, pp. 143-147.
Márquez, B.; Gibaja, J. F.; GonzÁlez, J. E.; IbÁÑez, J. J. y Palomo, A. (2008): "Projectile points as signs of violence in collective Burials during the $4^{\text {th }}$ and the $3^{\text {th }}$ millenia cal. BC in the north-east of the Iberian peninsula”. En Longo, L. y Skakun, N. (eds.): Prehistoric technology 40 years later: functional studies and the Russian legacy. Bar Int. Ser., 1783. Oxford: Archaeopress, pp. 312-326.

Odell, G. H. y Cowan, F. (1986): "Experiments with spears and arrows on animal targets", Journal of Field Archaeology, 13, pp. 195-211.

Palomo, A. y Gibaja, J. F. (2002): “Análisis de las puntas del sepulcro calcolítico de la Costa de can Martorell (Dosrius, Barcelona)". En Clemente, I.; Risch, R. y Gibaja, J. F. (eds.): Análisis funcional. Su aplicación al estudio de sociedades prehistóricas. BAR Int. Ser., 1073. Oxford: Archaeopress, pp. 243-249.

Palomo, A. y Gibaja, J. F. (2003): “Analisi tecnomorfològica / funcional i experimental de les puntes de fletxa". En Mercadal i Fernàndez, O. (coord.): La Costa de can Martorell (Dosrius, El Maresme). Mort i violencia en una comunitat del litoral català durant el tercer millenni a. C. Laietania, 14, pp. 179-214.

Pernter, P.; Gostner, P.; Vigl, E. E. y Rühli, F. J. (2007): "Radiologic proof for the Iceman's cause of Death (ca. 5,300 вр)", Journal of Archaeological Science, 34 (11), pp. 1784-1786.

Piqué, R.; Palomo, A.: Terradas, X.; Tarrús, J.; Buxó, R.; Bosch, A.; Chinchilla, J.; Bodganovic, I.; López, O. y SAN̂A, M. (2015): "Characterizing prehistoric archery: technical and functional analyses of the Neolithic bows from La Draga (Ne Iberian Peninsula)", Journal of Archaeological Science, 55, pp. 166-173.

Rodríguez Rellán, C. (2013): "Experimentando con proyectiles fabricados en materias primas distintas al sílex”. En Palomo, A.; Piqué, R. y Terradas, X. (eds.): Experimentación en arqueología. Estudio y difusión del pasado. Sèrie Monogràtica del MAC, 25.2. Gerona, pp. 285-292.

Rodríguez Rellán, C.; Fábregas, R. y Berriocha, E. (2011): "Shooting out the slate: working with flaked arrowheads made on thin-layeres rocks", Journal of Archaeological Science, 38 (8), pp. 1939-1948.

Rots, V. y Plisson, H. (2014): "Projectiles and the abuse of the use-wear method in a search for impact", Journal of Archaeological Science, 48, pp. 154-165.

SPINDLER, K. (1995): El hombre de los hielos. Barcelona: Galaxia Gutenberg. 